\title{
Different Zeroes of Interaction Energies As the Cause of Opposite Results on the Stabilizing Nature of $\mathrm{C}-\mathrm{H} \cdots \mathrm{O}$ Intramolecular Interactions
}

\author{
Mirosław Jabłoński* ${ }^{\dagger \dagger}$ and Guglielmo Monaco* ${ }^{* \dagger}$ \\ ${ }^{\dagger}$ Department of Quantum Chemistry, Nicolaus Copernicus University, 7-Gagarina St., PL-87 100 Toruń, Poland \\ ${ }^{\ddagger}$ Dipartimento di Chimica e Biologia, Universita di Salerno, Via Giovanni Paolo II, 132, 84084 Fisciano SA, Italy \\ Supporting Information
}

ABSTRACT: The interaction energy of the $\mathrm{C}-\mathrm{H} \cdots \mathrm{O}$ intramolecular interaction is estimated by several methods for a large group of systems possessing a quasi-cyclic six-membered ring. In the case of the geometry corrected method (GCM), the related rotamers method (RRM), and Espinosa's method (EM), the linear correlations between interaction energies and the electron density at the bond critical point have close slopes. The first and the last two methods yield almost systematically opposite results concerning the stabilizing/destabilizing character of the interaction, and their main difference is their zero of the interaction energy. An investigation on the limitations of reference energies has led to the introduction of the geometry corrected related rotamers method (GCRRM), estimating both stabilizing and destabilizing $\mathrm{C}-\mathrm{H} \cdots \mathrm{O}$ interactions. An extension of EM is proposed.

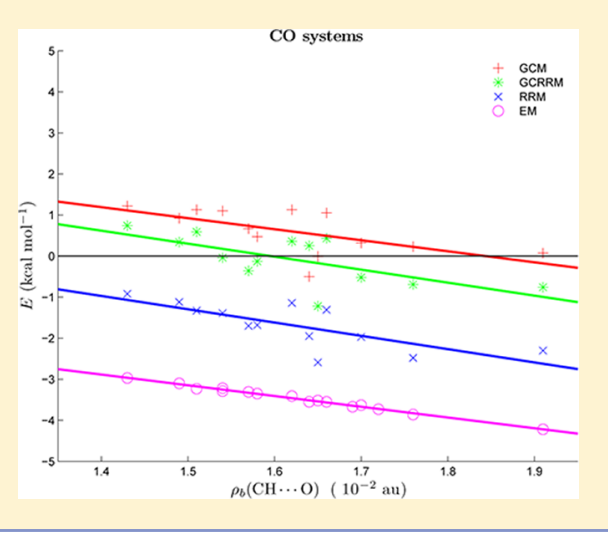

\section{INTRODUCTION}

In the world of inter- and intramolecular interactions, hydrogen bonds have a firm position due to their influence on a variety of bonding motifs, such as the spatial structure of ice, the secondary structure of proteins, or the DNA double helix. ${ }^{1-9}$ Thus, hydrogen bonds are nowadays the object of research in biochemistry, molecular engineering, and many other branches of science. In the majority of cases, hydrogen bonds, which may be labeled by the $\mathrm{X}-\mathrm{H} \cdots \mathrm{Y}$ formula, are formed if $\mathrm{X}$ and $\mathrm{Y}$ atoms are both much more electronegative than $\mathrm{H}$ and, moreover, $\mathrm{Y}$ possesses an electron lone-pair. Those systems suggested the development of electrostatic pictures of a hydrogen bond. ${ }^{10-13}$ On the other hand, the important role of a partial covalent character of a hydrogen bond was also proved. ${ }^{14-22}$ Both these views, rather than being incompatible, have been shown to be coarse-grained pictures within a single more complete theoretical framework. ${ }^{23}$ It is accepted at present that the $\mathrm{X}$ atom does not need to be much more electronegative than $\mathrm{H}$ and, furthermore, $\mathrm{Y}$ may in fact be any region of excess of the electron density. Thus, hydrogen bonds as $\mathrm{C}-\mathrm{H} \cdots \mathrm{Y}(\mathrm{Y}=\mathrm{O}, \mathrm{N}, \mathrm{S}$, etc. $)$ and $\mathrm{X}-\mathrm{H} \cdots \pi$ are nowadays widely known. ${ }^{7}$

The identification of a hydrogen bond can be based on its stabilizing character and thus on the negative contribution to the molecular energy. However, the usual definition of the hydrogen bond energy as the difference of energies of hydrogen bonded and isolated moieties is not straightforwardly extended to intramolecular hydrogen bonds. This results from the lack of a unique reference system devoid of a hydrogen bond. ${ }^{8,24-28}$ Lacking any assessment on the stabilizing character of an $\mathrm{X}-$
$\mathrm{H} \cdots \mathrm{Y}$ interaction, the structural analogy with intermolecular hydrogen bonds is often used to consider it as a hydrogen bond. Of course, in the case of standard hydrogen bonds where the hydrogen atom interacts with two highly electronegative atoms as e.g. $\mathrm{O}-\mathrm{H} \cdots \mathrm{O}, \mathrm{N}-\mathrm{H} \cdots \mathrm{O}$, the stabilizing character is rather certain; however, this is not the case if $\mathrm{X}$ is not much more electronegative than $\mathrm{H}$ as, for instance, in the case of the $\mathrm{C}-\mathrm{H} \cdots \mathrm{O}$ interaction. Thus, the study of weak intramolecular hydrogen bonds would most benefit from methods to estimate their interaction energy.

Several such methods have been proposed, differing for the system(s) chosen as reference to compute the molecular total energy deprived of the contribution of the intramolecular hydrogen bond. ${ }^{26,27,29-47}$ Even if applied within their operating limits, ${ }^{26-28}$ different methods can give a rather wide range of energy values, which is a source of concern, especially if the interaction is particularly weak. Contrary results obtained by methods differing for their reference system(s) call for a nontrivial assessment of the quality of these reference system(s).

This problem formally does not exist in the case of referencefree methods. One of these methods is the quantum theory of atoms in molecules (QTAIM) developed by Bader. ${ }^{48,49}$ According to QTAIM, the joint presence of a bond path (BP) and a bond critical point (BCP) is proclaimed to indicate the bonding character of an interaction between any two atoms linked by that bond path. ${ }^{50,51}$ Not surprisingly, the appealing

Received: February 4, 2013

Published: June 16, 2013 
<smiles></smiles><smiles>O=CC=CNC=O</smiles>

NO1<smiles>C1=C[SH]=CNC1</smiles>

NS1<smiles>[CH]1[CH]OC=CC=C1</smiles>
$\mathrm{CO} 3$<smiles>C=C1[CH]OC=CC=C1</smiles>

CO8<smiles>FC=C1[CH]OC=CC=C1</smiles>

C013<smiles></smiles><smiles></smiles>

NO2<smiles>CC1=CC=[SH][CH]NC1</smiles>

NS2<smiles>FC1(F)[CH]OC=CC=C1</smiles>

$\mathrm{CO} 4$<smiles>C1=CCOC=C1</smiles>

OS1<smiles></smiles>

NO3<smiles>CC1=CC=[SH][CH]N1</smiles>

NS3<smiles>O=C([O-])[O-]</smiles>

CO5<smiles>C=C1[CH]OC=CC1C</smiles>

CO9<smiles>FC(F)=C1[CH]OC=CC=C1</smiles>

CO10<smiles>O=C1[CH][SH]=CC=C1</smiles>

CS1<smiles>O=C1[CH]OC=CC=C1</smiles>

CO1<smiles>CC1C=CO[CH]C1</smiles>

CO6<smiles>CC1=CC(=C(F)F)[CH]OC1</smiles>

C011<smiles>S=C1C=CC=[SH]C1</smiles>

cs2<smiles>S=C1[CH]OC=CC=C1</smiles>

$\mathrm{CO} 2$<smiles></smiles><smiles>ClC(Cl)=C1[CH]OC=CC=C1</smiles>

CO12<smiles>C=C1C=COC=C1</smiles>

C014<smiles>[CH]1OC=CC=C2C=CCC=C12</smiles>

C015<smiles></smiles>

Co16

Figure 1. Closed forms of model systems.

clear-cut definition of bonding interactions within QTAIM has been used several times in the discussion of intramolecular interactions. $^{28,51-53}$ However, the BP-BCP assessment of the stabilizing character of an interaction can lead to the disagreement with the conventional Lewis-based descriptions of chemical bond patterns and its usefulness in proving a stabilizing character of a bond has been criticized by several authors. ${ }^{2,54-66}$ Cioslowski and Mixon, for example, claimed that the bond critical points in the electron density are not necessarily associated with bonding interactions and that sterically crowded molecules can also show a bond path which, however, should be interpreted as indicating a nonbonding destabilizing interaction instead of a stabilizing one. ${ }^{55-57}$ Very recently, a similar conclusion has been reached ${ }^{28}$ for a group of molecules possessing the intramolecular contact of the $\mathrm{X} \cdots \mathrm{O}(\mathrm{X}=$ halogen $)$ type. On the basis of few estimating procedures, it was shown ${ }^{28,66}$ that $\mathrm{X} \cdots \mathrm{O}$ interactions are in fact destabilizing, although a bond path and the corresponding bond critical point were found in this case. Also it was reported earlier $^{67,68}$ that $\mathrm{C}-\mathrm{H} \cdots \mathrm{O}$ or $\mathrm{C}-\mathrm{H} \cdots \mathrm{S}$ interactions, which are present in closed conformers of a large group of systems, have destabilizing character, even though both these types of interactions would most likely be immediately classified as stabilizing.

On the basis of the interacting quantum atoms ${ }^{69}$ approach (IQA), Pendás et al. ${ }^{70}$ have shown that bond paths are formed between atoms that are characterized by the preferred exchange energy channels. More precisely, an atom A forms a bond path to an atom $\mathrm{B}$ if the $\mathrm{A} \cdots \mathrm{B}$ interaction provides the largest exchange-correlation stabilization among other possible interatomic contacts. In spite of a large $\mathrm{A} \cdots \mathrm{B}$ exchange-correlation stabilization, that can be understood as energetic stabilization due to electron spin pairing, other energy terms may lead to an overall increase of the total energy of a system. $^{70}$ As a consequence, IQA explicates the presence of a bond path between different pairs of atoms that normally would not be investigated as forming a chemical bond. An example can be $\mathrm{H} \cdots \mathrm{H}$ and $\mathrm{H} \cdots \mathrm{C}$ contacts in planar biphenyl and in some endohedral complexes, respectively. ${ }^{70}$ Very recently similar conclusion was obtained in the case of various intramolecular 


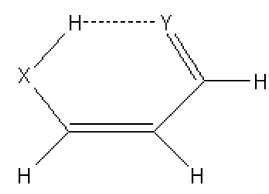

$\mathrm{CCC}$

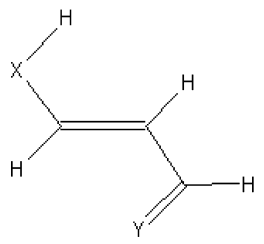

CTC
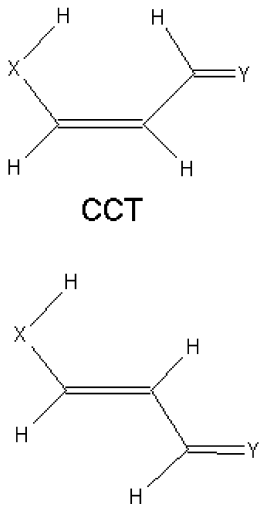

$\mathrm{CTT}$
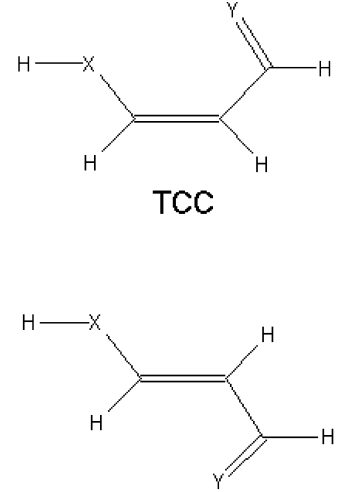

TTC
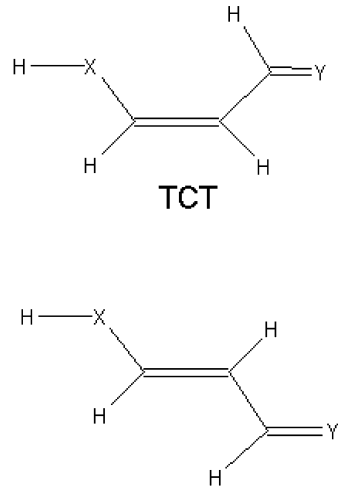

TाT

Figure 2. Identifiable eight conformers of a model system.

$\mathrm{O} \cdots \mathrm{Y}(\mathrm{Y}=\mathrm{O}, \mathrm{S}, \mathrm{F}, \mathrm{Cl}, \mathrm{Br})$ interactions. Moreover, some of these interactions $(\mathrm{O} \cdots \mathrm{F}$ and some $\mathrm{O} \cdots \mathrm{Cl}$ ) appeared to be repulsive based on the IQA framework. ${ }^{71}$ Repulsive interactions have also been found in the case of a pair of either $\mathrm{X}$ anions or $M$ cations in diverse $\mathrm{M}_{2} \mathrm{X}_{2}$ systems $(\mathrm{M}=\mathrm{Li}, \mathrm{Na}, \mathrm{K} ; \mathrm{X}=\mathrm{H}, \mathrm{OH}$, $\mathrm{F}, \mathrm{Cl}$ ), despite their bonding character within QTAIM. ${ }^{65}$ Thus, the presence of a bond path between a pair of atoms does not necessarily indicate a stabilizing character for the interaction of those atoms. ${ }^{28,54-66,70,71}$

The aim of this article is twofold. First of all, the energy of the intramolecular $\mathrm{X}-\mathrm{H} \cdots \mathrm{Y}$ interaction will be estimated for a large group of systems. We will show that the eight different methods used in this study and presented in the Methodology give estimates of the energy of the intramolecular interaction spanning a wide range. As a second step, we will proceed to grade these methods according to their performance, first in giving trends expected for chemically close systems, and then by investigating their correlation with $\rho_{\mathrm{b}}$-the electron density at the BCP. Indeed, correlations between hydrogen bond energies and $\rho_{\mathrm{b}}$ are known for dimers. ${ }^{17,72-79}$ We investigate systems based on a quasi-cyclic six-membered ring and mostly possessing a weak intramolecular $\mathrm{C}-\mathrm{H} \cdots \mathrm{O}$ interaction. However, other types of interactions $(\mathrm{O}-\mathrm{H} \cdots \mathrm{O}, \mathrm{O}-\mathrm{H} \cdots \mathrm{S}$, $\mathrm{N}-\mathrm{H} \cdots \mathrm{O}, \mathrm{N}-\mathrm{H} \cdots \mathrm{S}$ ) are investigated as well to test estimating methods in those cases where the presence of the intramolecular hydrogen bond is expected. As a consequence, in this case all methods should lead to clearly negative values of the interaction energy.

All model systems investigated in the present studies are shown in Figure 1. Most of them possess either four or eight conformers. Rather than using different notations for the dihedral angles on single (s-cis/s-trans) and double bonds $(\mathrm{Z} / \mathrm{E}$, cis/trans) or the sp/ap notation, we will label conformers by means of the $\mathrm{C} / \mathrm{T}$ (cis/trans) notation suggested by IUPAC for polymers. ${ }^{80}$ The conformational designation is specified by the consecutive torsion angles along the chain of skeleton atoms which starts at the hydrogen of the $\mathrm{X}-\mathrm{H}$ subunit and ends at its acceptor Y (see Figure 2 for their labels in the case of eight conformers). If the proton donor group is symmetrical as, e.g. in the case of $-\mathrm{NH}_{2}$, then the four conformers are labeled as CC, CT, TC, and TT.

\section{METHODOLOGY}

In this section, we discuss the methods used to estimate the $\mathrm{X}-$ $\mathrm{H} \cdots \mathrm{Y}$ interaction energies and we give some computational details. The eight methods considered in this paper belong to three different families: (1) conformational methods, (2) isodesmic methods, and (3) reference-free methods. Within reference-free methods, we have considered the simple Espinosa's method ${ }^{41}$ (EM). Some preliminary consideration on the general limitations of these methods is in order.

The energy lowering obtained in the formation of a diatomic molecule with respect to isolated atoms in given quantum states is a well-defined quantity and it is safely used as the definition of the bond energy. This definition cannot be easily extended to polyatomic systems, where some kind of energy partitioning must be used, either explicitly or implicitly. In the formation of intermolecular complexes, a single couple of atoms is often brought to a closer distance than the other ones. That is why it is common to disregard interactions between all farther couples of atoms and to attribute all the energy change to the interaction energy of the former couple only. The energy partitioning issue is more relevant for the intramolecular interactions, which lack a unique reference system devoid of the interaction of interest, like the isolated molecules in the intermolecular case. Various methods can then be envisaged differing for the system(s) used to build the reference. Conformational methods, to be discussed immediately, take advantage of the presence of one or more conformers devoid of the close $\mathrm{X}-\mathrm{H} \cdots \mathrm{Y}$ interaction. In the following a method will be shortened by an M-ending string of capitals (e.g., OCM), and that string will be used to label the model-dependent interaction energy (e.g., $\left.E^{\mathrm{OCM}}\right)$.

Conformational Methods. Conformational methods use total energies of two or more conformers to estimate the energy of the intramolecular $\mathrm{X}-\mathrm{H} \cdots \mathrm{Y}$ interaction. Among them, the simplest and most often used ${ }^{81}$ is the open-closed method. $^{29,30}$

Open-Closed Method (OCM). For a molecular energy given by the summation of bond contributions which do not depend upon conformation, the energy difference between the closed form and any reference open form could be used to retrieve the $\mathrm{X}-\mathrm{H} \cdots \mathrm{Y}$ interaction energy:

$$
E^{\mathrm{OCM}}=E(\text { closed })-E(\text { open })
$$

This method is a good example to show that many variants of a given method can exist. First of all, one has to decide which open system is to be used as a reference. ${ }^{26-28}$ Changing the reference open form, the estimation of the interaction energy can change considerably. Following most studies, ${ }^{81}$ in the 
present paper the single conformer CT (or CCT) will be utilized as a reference for the estimation of $E^{\mathrm{OCM}}$. In many instances the open reference form is significantly different from the closed form, and moreover, its full geometry optimization leads to some other new important interaction(s) (either stabilizing or destabilizing). As a consequence, the estimated value of the hydrogen bond energy is contaminated with some other energy contributions that bring about the low reliability of its value. ${ }^{27,28,82}$ In some cases, it has been suggested that rather a partial instead of full geometry optimization of the reference system should be more reliable. ${ }^{27}$

The other question is on whether or not the geometry of the open reference system should be optimized at all. This question seems to be investigated only sporadically, ${ }^{25,27,28,32}$ and only in few papers are some approaches proposed. ${ }^{25-27,29,30,32}$

Geometry Corrected Method (GCM). As just reported, in studies of intramolecular hydrogen bonds where OCM is used, the CT (or CCT) conformer very often acts as the open reference form. ${ }^{81}$ This, however, possesses an important new $\mathrm{H} \cdot \cdots \mathrm{H}$ interaction (see Figure 2). In order to avoid the use of this conformer a variant of OCM has recently been proposed in the estimation of the hydrogen bond interaction energy in 3aminopropenal (NO1) and 3-aminopropenthial (NS1). ${ }^{26}$ That variant, called "method A" in ref 26 and hereafter denoted as the geometry corrected method (GCM), takes advantage of the two conformers TC (CTC) and TT (CTT). Rather than selecting the total energy of either of those two conformers, GCM considers their averaged value as a reference. Importantly, to take into account corrections for the geometry changes which take place if transitions to other conformers are considered, these two conformers are built with exactly the same values of geometrical parameters as in the closed conformer CC (CCC). For future convenience, these nonoptimized geometries, called (TC,f) and (TT,f) in ref 26 , will be labeled as $\mathrm{TC}_{\mathrm{CC}}$ and $\mathrm{TT}_{\mathrm{CC}}$. Similarly, we will write $\mathrm{CTC}_{\mathrm{CCC}}$ and $\mathrm{CTT}_{\mathrm{CCC}}$ for the fictitious nonoptimized geometries of CTC and CTT conformations, respectively. They are both obtained using the internal coordinates of the CCC conformer. Eventually, the operative equations of GCM are

$$
E^{\mathrm{GCM}}=E(\mathrm{CC})-\frac{1}{2}\left[E\left(\mathrm{TC}_{\mathrm{CC}}\right)+E\left(\mathrm{TT}_{\mathrm{CC}}\right)\right]
$$

or

$$
E^{\mathrm{GCM}}=E(\mathrm{CCC})-\frac{1}{2}\left[E\left(\mathrm{CTC}_{\mathrm{CCC}}\right)+E\left(\mathrm{CTT}_{\mathrm{CCC}}\right)\right]
$$

if $\mathrm{R} \neq \mathrm{H}$ in $-\mathrm{XRH}$, thus if the proton donor group has no symmetry. Details of the definition and comprehensive discussion of the reliability of expressions 2 and 3 for the energy contribution due to the intramolecular interaction can be found elsewhere. ${ }^{26,67}$

The usage of this method, that is believed ${ }^{26,67}$ to be more reliable than the more plain OCM, is rather limited to structures which do not possess any bulky substituents and, moreover, are rather planar. If these assumptions are satisfied, then GCM yields similar energy values as OCM. Importantly, GCM leads to intuitively correct relations among estimated energy values e.g. if substituent effects or molecular flattening is investigated.

Related Rotamers Method (RRM). We also used the related rotamers method $(\mathrm{RRM})^{39,40}$ which has the use of total energies of four conformers and defines the energy of the intramolecular interaction in the closed form as follows:

$$
\begin{aligned}
& E^{\mathrm{RRM}}=[E(\mathrm{CC})-E(\mathrm{CT})]-[E(\mathrm{TC})-E(\mathrm{TT})] \\
& E^{\mathrm{RRM}}=[E(\mathrm{CCC})-E(\mathrm{CCT})]-[E(\mathrm{CTC})-E(\mathrm{CTT})]
\end{aligned}
$$

In eq 4, each bond with a given conformation appears twice with opposite signs. Therefore, in the absence of nonadditive conformation-dependent bond energies, $E^{\mathrm{RRM}}$ would be zero. The $\mathrm{X}-\mathrm{H} \cdots \mathrm{Y}$ interaction appears only in the CC conformation and if it has any effect on energy, it will directly influence $E^{\mathrm{RRM}}$. However any interaction which is specific of a given conformer, as the $\mathrm{H} \cdots \mathrm{H}$ repulsion in the CT conformer, will also affect $E^{\mathrm{RRM}}$.

Isodesmic Methods (IM). Isodesmic reactions ${ }^{36-38}$ which are "transformations in which the numbers of bonds of each formal type are conserved and only the relationships among the bonds are altered" 38 are generally considered to provide a useful tool for the estimation of intramolecular interaction energies. $^{27,28,32,33,43,83,84}$ The reliability of this approach is based on the assumption that the total energy of a molecule can be partitioned into energies of chemically recognizable fragments and that those energies are transferable between different molecules which involve similar chemical units. When applied to our case, a general scheme of the isodesmic method can be displayed as in Figure 3, where the molecular skeleton is

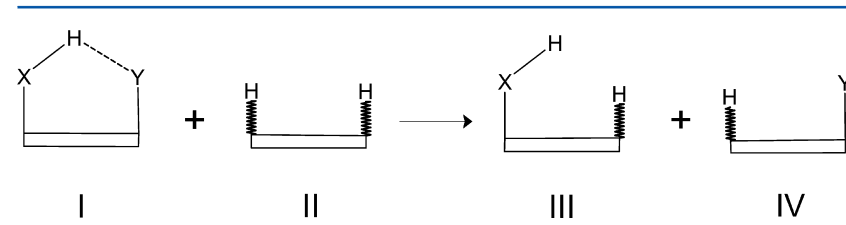

Figure 3. Schematic isodesmic reaction used for investigated systems.

marked as a box for simplicity. Those $\mathrm{C}-\mathrm{H}$ bonds in component molecules II, III, and IV which are not present in the parent molecule I are marked by the zigzag bond line. By comparison of both sides of the isodesmic reaction (Figure 3 ), one can see that formally all bonds, but the one being on the left-hand side of this reaction, are also present on the righthand side, i.e. the number and type of bonds are conserved if this reaction is considered. The only bond which is missing on the right-hand side is the $\mathrm{H} \cdots \mathrm{Y}$ contact that is present in the parent molecule I. Thus, the energy of this contact can be obtained by the formula

$$
\begin{aligned}
& E^{\mathrm{IM}}=E(\mathrm{I})-E_{\text {ref }}^{\mathrm{IM}}(\mathrm{I}) \\
& E_{\text {ref }}^{\mathrm{IM}}(\mathrm{I})=E(\mathrm{III})+E(\mathrm{IV})-E(\mathrm{II})
\end{aligned}
$$

where $E(I)$ is the total energy of the fully optimized system I and the combination of total energies of systems II, III, and IV is used to obtain the reference energy $E_{\mathrm{ref}}^{\mathrm{IM}}(\mathrm{I})$. Notably, reactions based on the scheme of Figure 3 are also homodesmotic reactions, which are a subclass of isodesmic reactions. ${ }^{85}$

Actually, as for conformational methods, the isodesmic approach can be applied according to many variants. ${ }^{27,28,43,85}$ One issue, for example, is which geometries are to be used for the molecules considered for the computation of $E_{\mathrm{ref}}^{\mathrm{IM}}(\mathrm{I}) .^{27,28,43}$ For instance, one may optimize geometries of these molecules and then all total energies used in eq 7 will correspond to fully optimized systems. The interaction energy obtained in this way will be henceforth denoted as $E^{\mathrm{IM}}$. One may also consider geometries for the auxiliary systems II, III, and IV which are the same as the geometry of the investigated system I-a possibility 
which has been rarely considered. ${ }^{27}$ Then, however, another issue arises. Namely, how to treat those $\mathrm{C}-\mathrm{H}$ bonds which are not present in the parent molecule I, i.e. those which are marked by the zigzag bond line in Figure 3. For sure there may exist few conceivable approaches. One may, for example, ascribe them the lengths of either $\mathrm{C}-\mathrm{X}$ or $\mathrm{C}-\mathrm{Y}$ bonds in molecule I. Energy value obtained in this way will be henceforth denoted as $E^{\mathrm{IM}-\text { long }}$. One may also optimize lengths of these bonds (zigzag $\mathrm{C}-\mathrm{H}$ bonds in Figure 3 ) while keeping frozen all other geometrical parameters or assume their values fixed to, for example, $1 \AA$. Energy values obtained by these approaches will be henceforth denoted as $E^{\mathrm{IM}-\mathrm{o}}$ and $E^{\mathrm{IM}-1}$, respectively. Considering the signs in eq 7 , the use of nonoptimized structures for II, III, and IV should lead to a less negative value of $E_{\text {ref }}^{\mathrm{IM}}(\mathrm{I})$ and, as a consequence, to the overestimation of $E^{\mathrm{IM}}$. Nevertheless, we also consider this variant of IM taking into consideration that the energies so obtained could give a better correlation with $\rho_{\mathrm{b}}$.

It should also be mentioned that any dimerization model, where the dimer has the $\mathrm{X}-\mathrm{H} \cdots \mathrm{Y}$ contact and the monomers are isolated, is also an isodesmic method. Dimerization models have been previously considered for the evaluation of weak intramolecular interaction, ${ }^{26,66}$ and we did not intend to consider them here in any systematic way.

Espinosa's Method (EM). Once a BCP is located, calculation of the electronic potential energy density, $V_{\mathrm{b}}$, at that point makes possible to take advantage of Espinosa's method $(\mathrm{EM})^{41}$

$$
E^{\mathrm{EM}}=\frac{1}{2} V_{\mathrm{b}}
$$

that was derived for intermolecular $\mathrm{X}-\mathrm{H} \cdots \mathrm{O}(\mathrm{X}=\mathrm{C}, \mathrm{N}, \mathrm{O})$ interactions. The, by definition, negative value of $V_{\mathrm{b}}$ will always yield a negative value of $E^{\mathrm{EM}}$, thus indicating the stabilizing nature of any interaction with a BCP. Although this appealing correlation stands well to reason for intermolecular interactions, it is less obvious for intramolecular interactions. Indeed, the electronic potential energy density, present in this formula, was interpreted as the pressure exerted by the system on electrons around the BCP of the $\mathrm{H} \cdots \mathrm{Y}$ interaction. ${ }^{41}$ Thus we expect that the close proximity of $\mathrm{H}$ and $\mathrm{Y}$ atoms, which can be forced by strain forces within the skeleton, will lead to high absolute values of $V_{\mathrm{b}}$ and, as a consequence, to significantly negative values of interaction energies, therefore indicating hydrogen bonds even in those cases where they instead occur to be destabilizing contacts if other estimating procedures are used. Some shortcomings of EM have very recently been pointed out by Nikolaienko et al. ${ }^{47}$

Computational Details. Geometries and energies have been computed by means of the Gaussian 09 set of $\operatorname{codes}^{86}$ at the level of the second-order Møller-Plesset perturbation theory (MP2) $)^{87}$ with aug-cc-pVTZ basis set. ${ }^{88,89}$ For fully optimized geometries the frequency analysis has been used to verify that structures correspond to the ground state stationary points. No imaginary frequencies were found in those cases. The QTAIM based analysis of the electron density topology at the bond critical point (BCP) of the $\mathrm{H} \cdots \mathrm{Y}$ interaction has been obtained by means of the Xaim program by Ortiz and Bo. ${ }^{90}$ Electron density $\left(\rho_{\mathrm{b}}\right)$, its Laplacian $\left(\nabla^{2} \rho_{\mathrm{b}}\right)$, total electronic energy density $\left(H_{\mathrm{b}}\right)$, and its two components, potential and kinetic electronic energy densities ( $V_{\mathrm{b}}$ and $G_{\mathrm{b}}$, respectively), have been computed using the MP2 wave function (Density = Current option in Gaussian).
A two-tailed $t$ test for a nonrandom correlation of a set of $n$ pairs of values $X_{1}, X_{2}, \ldots, X_{n}$ and $Y_{1}, Y_{2}, \ldots, Y_{n}$ was performed computing the correlation coefficient $r=\left[\sum_{i}\left(X_{i}-\bar{X}\right)\left(Y_{i}-\right.\right.$ $\bar{Y})] /\left\{\left[\sum_{i}\left(X_{i}-\bar{X}\right)^{2} \sum_{i}\left(Y_{i}-\bar{Y}\right)^{2}\right]^{1 / 2}\right\}$ and the value $T=r[(n-$ $\left.2) /\left(1-r^{2}\right)\right]^{1 / 2}$. The statistics of $T$ follows a Student's $t$ distribution with $\nu=n-2$ degrees of freedom. Values of $|T|$ higher than $t_{\nu, 0.025}$ indicate a correlation that is significant at the $95 \%$ confidence level. $^{91}$

\section{RESULTS AND DISCUSSION}

Planar vs Twisted Structure of the Closed Form of a Molecule. In this subsection we discuss some geometrical features of investigated systems (Figure 1). In the last two columns of Table 1 values of dihedral angles that define positions of $\mathrm{H}$ and $\mathrm{Y}$ atoms of the $\mathrm{H} \cdots \mathrm{Y}$ contact with respect to the molecular skeleton are included. With the exception of O01, all investigated molecules with "standard" hydrogen bonds, i.e. molecules of the OO, OS, NO, and NS type, have a

Table 1. Values of Geometrical Parameters (Distances in Angstroms, Angles in Degrees) Describing the $\mathrm{X}-\mathrm{H} \cdots \mathrm{Y}$ Contact in Fully Optimized and Planarized ${ }^{a}$ Closed Forms of Investigated Systems

\begin{tabular}{|c|c|c|c|c|c|c|}
\hline system & $d_{\mathrm{XH}}$ & $\Delta d_{\mathrm{XH}}^{b}$ & $d_{\mathrm{H} \ldots \mathrm{Y}}$ & $\alpha_{\mathrm{XHY}}$ & $\theta_{\mathrm{H}}$ & $\theta_{\mathrm{Y}}$ \\
\hline 001 & 0.9656 & 0.0036 & 2.21 & 126.4 & 67.6 & 2.9 \\
\hline 002 & 1.0016 & 0.0384 & 1.64 & 149.0 & 0.0 & 0.0 \\
\hline OS1 & 1.0062 & 0.0419 & 2.00 & 152.7 & 0.0 & 0.0 \\
\hline NO1 & 1.0151 & 0.0107 & 1.91 & 129.8 & 0.0 & 0.0 \\
\hline $\mathrm{NO} 2$ & 1.0137 & 0.0087 & 1.90 & 129.2 & 0.0 & 0.0 \\
\hline NO3 & 1.0167 & 0.0116 & 1.87 & 132.0 & 0.0 & 0.0 \\
\hline NS1 & 1.0234 & 0.0187 & 2.18 & 137.2 & 0.0 & 0.0 \\
\hline NS2 & 1.0228 & 0.0179 & 2.15 & 137.1 & 0.0 & 0.0 \\
\hline NS3 & 1.0247 & 0.0195 & 2.15 & 139.2 & 0.0 & 0.0 \\
\hline \multirow[t]{2}{*}{ CS1 } & 1.0990 & -0.0013 & 2.70 & 108.7 & 19.5 & 33.8 \\
\hline & 1.0944 & -0.0059 & 2.63 & 125.0 & 0.0 & 0.0 \\
\hline \multirow[t]{2}{*}{ CS2 } & 1.0861 & -0.0012 & 2.61 & 118.1 & 10.9 & 29.5 \\
\hline & 1.0847 & -0.0026 & 2.56 & 128.0 & 0.0 & 0.0 \\
\hline \multirow[t]{2}{*}{$\mathrm{CO1}$} & 1.0955 & -0.0039 & 2.33 & 116.5 & 7.0 & 22.2 \\
\hline & 1.0944 & -0.0050 & 2.31 & 119.6 & 0.0 & 0.0 \\
\hline \multirow[t]{2}{*}{$\mathrm{CO} 2$} & 1.0847 & -0.0020 & 2.26 & 121.8 & 1.3 & 7.1 \\
\hline & 1.0847 & -0.0020 & 2.26 & 122.0 & 0.0 & 0.0 \\
\hline \multirow[t]{2}{*}{$\mathrm{CO} 3$} & 1.0852 & 0.0000 & 2.31 & 118.6 & 18.4 & 14.2 \\
\hline & 1.0836 & -0.0017 & 2.27 & 125.8 & 0.0 & 0.0 \\
\hline \multirow[t]{2}{*}{$\mathrm{CO} 4$} & 1.0840 & -0.0019 & 2.29 & 116.5 & 16.3 & 16.8 \\
\hline & 1.0829 & -0.0029 & 2.25 & 122.8 & 0.0 & 0.0 \\
\hline $\cos$ & 1.0812 & -0.0007 & 2.18 & 126.6 & 0.0 & 0.0 \\
\hline \multirow[t]{2}{*}{$\mathrm{CO6}$} & 1.0864 & 0.0014 & 2.33 & 111.1 & 27.9 & 17.8 \\
\hline & 1.0831 & -0.0019 & 2.23 & 125.7 & 0.0 & 0.0 \\
\hline \multirow[t]{2}{*}{$\mathrm{CO} 7$} & 1.0838 & -0.0014 & 2.27 & 114.7 & 17.2 & 21.8 \\
\hline & 1.0822 & -0.0030 & 2.22 & 122.7 & 0.0 & 0.0 \\
\hline $\mathrm{CO} 8$ & 1.0804 & -0.0016 & 2.29 & 120.1 & 0.0 & 0.0 \\
\hline CO9 & 1.0800 & -0.0017 & 2.25 & 120.0 & 0.0 & 0.0 \\
\hline CO10 & 1.0776 & -0.0002 & 2.25 & 117.8 & 0.0 & 0.0 \\
\hline CO11 & 1.0772 & -0.0005 & 2.22 & 117.7 & 0.0 & 0.0 \\
\hline $\mathrm{CO} 12$ & 1.0804 & -0.0002 & 2.24 & 120.3 & 0.0 & 0.0 \\
\hline $\mathrm{CO13}$ & 1.0797 & -0.0008 & 2.28 & 117.9 & 0.0 & 0.0 \\
\hline CO14 & 1.0782 & -0.0026 & 2.28 & 119.1 & 0.0 & 0.0 \\
\hline CO15 & 1.0799 & -0.0010 & 2.23 & 122.8 & 0.0 & 0.0 \\
\hline CO16 & 1.0800 & -0.0011 & 2.23 & 122.7 & 0.0 & 0.0 \\
\hline
\end{tabular}

${ }^{a}$ Second lines wherever needed. ${ }^{b}$ Change of the $\mathrm{X}-\mathrm{H}$ bond length with respect to the open $\mathrm{CT}$ or CCT conformer. 
conjugated $\pi$ system linking $\mathrm{X}-\mathrm{H}$ and $\mathrm{Y}$ subunits and, as expected, are planar. For the hydrogen bonds of these molecules, Gilli et al. $^{92}$ have coined the special term resonance-assisted hydrogen bond (RAHB), which is meant to account for the fact that a proton shift from $\mathrm{X}$ to $\mathrm{Y}$ is associated with the interchange of two nonzwitterionic tautomeric forms. Non-RAHBs are more prone to escape planarity as evidenced by $\mathbf{O O 1}$ and many of the CY systems. Actually, $\pi$ conjugation-even if not of the kind required to have RAHB - is often associated with planarity (CO8-CO16), although not always (CS1-CS2 and CO1-CO2). With the exception of $\mathbf{C O 5}$, all $\mathrm{CY}$ systems devoid of the $\pi$ connecting network are bent in their optimized geometry. The out-of-plane distortion is then enhanced by the insertion of the $-\mathrm{CH}_{3}$ group in the molecular skeleton (compare e.g. either $\mathrm{CO} 3$ with $\mathrm{CO} 6$ or $\mathrm{CO} 4$ with $\mathrm{CO} 7$ ).

Data of column three in Table 1 indicate that the formation of the $\mathrm{C}-\mathrm{H} \cdots \mathrm{Y}(\mathrm{Y}=\mathrm{O}, \mathrm{S})$ contact leads to a small shortening of the $\mathrm{C}-\mathrm{H}$ bond, whereas one observes a characteristic larger elongation of the $\mathrm{X}-\mathrm{H}$ bond in the case of standard intramolecular hydrogen bonds. Similar shortenings offered the reason to introduce the so-called improper, blue-shifting hydrogen bonds ${ }^{93-96}$ to oppose them to standard hydrogen bonds. In the theoretical picture of $\mathrm{Li}$ et al., ${ }^{97}$ both the blue shift and the shortening of the $\mathrm{X}-\mathrm{H}$ bond are a consequence of the steric push exerted on the hydrogen by the $\mathrm{Y}$ fragment. In the case of improper, blue-shifting hydrogen bonds, the bond shortening is greater than bond lengthening when the total energy reaches its minimum. ${ }^{97}$ On the other hand, in the picture of Joseph and Jemmis, ${ }^{98}$ these features arise as a consequence of the increased electronic pull exerted by $\mathrm{X}$ on the hydrogen in presence of the proton acceptor $Y$. The picture of $\mathrm{Li}$ et al. has been previously used to interpret the nonplanar geometries of many $\mathbf{C O}$ as well as other systems possessing blue-shifting hydrogen bonds. ${ }^{28,67,68,99}$ The energy needed to planarize them (see Table S1 in the Supporting Information) could be interpreted as the penalty needed to force a close contact between the hydrogen and the oxygen.

Energy of the Intramolecular $\mathrm{C}-\mathrm{H} \cdots \mathrm{O}$ Interaction. To estimate the energy of the intramolecular $\mathrm{X}-\mathrm{H} \cdots \mathrm{Y}$ interaction within the investigated set of 27 molecules, the 8 methods detailed in the Methodology have been utilized first. Three of them belong to the conformational family, four to the isodesmic family, and one (EM) to the reference-free family. Estimated values of interaction energies are collected in Table 2 (values of $E^{\mathrm{IM}-\text { long }}, E^{\mathrm{IM}-\mathrm{o}}$, and $E^{\mathrm{IM}-1}$ are gathered in Supporting Information Table S2).

It can be noticed that in most cases the weakest stabilization is predicted by OCM, whereas the strongest stabilization is predicted either by the isodesmic methods (NO, NS, and OS1 systems) or by EM (OO2, CO, and CS systems). In almost all cases, within the conformational family, the methods yielding the weakest and strongest stabilizations are OCM and RRM, respectively. This can be understood by comparison of eqs 4 (or 5) and 1, leading to

$$
E^{\mathrm{RRM}}-E^{\mathrm{OCM}}=E(\mathrm{TT})-E(\mathrm{TC})
$$

Since in most cases the extended (relaxed) TT conformer is more stable than TC, i.e. its total energy is lower, the right-hand side difference in eq 9 is negative, yielding higher stabilizations if RRM is used. Thus, interactions which are found to be destabilizing on the basis of OCM are less destabilizing or are even stabilizing if RRM is used. In other words, RRM considers
Table 2. Estimated Values of the Interaction Energy (kcal/ mol) of the $\mathrm{X}-\mathrm{H} \cdots \mathrm{Y}$ Contact in Fully Optimized and Planarized $^{a}$ Closed Forms of Investigated Systems

\begin{tabular}{|c|c|c|c|c|c|c|}
\hline system & $E^{\mathrm{OCM}}$ & $E^{\mathrm{GCM}}$ & $E^{\mathrm{RRM}}$ & $E^{\mathrm{IM}}$ & $E^{\mathrm{EM}}$ & $E^{\mathrm{GCRRM}}$ \\
\hline 001 & -5.01 & -6.15 & & -1.50 & -3.66 & \\
\hline 002 & -9.94 & -10.53 & -11.95 & -11.50 & -19.78 & -10.40 \\
\hline OS1 & -9.28 & -11.00 & -11.93 & -12.59 & -12.59 & -10.62 \\
\hline NO1 & -7.62 & -6.50 & -9.11 & -11.83 & -8.81 & -7.54 \\
\hline $\mathrm{NO} 2$ & -5.34 & -4.68 & -8.57 & -10.70 & -9.08 & -5.23 \\
\hline NO3 & -7.64 & -10.50 & -7.70 & -11.34 & -9.88 & -5.21 \\
\hline NS1 & -7.83 & -8.38 & -9.56 & -14.21 & -7.85 & -8.01 \\
\hline NS2 & -5.23 & -6.98 & -8.81 & -13.41 & -8.31 & -6.75 \\
\hline NS3 & -7.69 & -13.23 & -8.99 & -13.63 & -8.42 & -7.16 \\
\hline \multirow[t]{2}{*}{ CS1 } & 2.83 & 0.26 & 0.34 & 3.85 & -2.62 & 1.84 \\
\hline & 4.31 & 1.77 & 1.82 & 5.33 & -2.69 & 3.32 \\
\hline \multirow[t]{2}{*}{ CS2 } & 2.96 & 0.40 & 0.50 & 1.63 & -2.84 & 1.85 \\
\hline & 3.53 & 1.23 & 1.07 & 2.20 & -3.12 & 2.42 \\
\hline \multirow[t]{2}{*}{$\mathrm{CO} 1$} & 1.11 & 1.22 & -0.92 & 4.27 & -2.97 & 0.74 \\
\hline & 1.24 & 1.58 & -0.79 & 4.40 & -3.10 & 0.87 \\
\hline \multirow[t]{2}{*}{$\mathrm{CO} 2$} & 0.86 & 1.13 & -1.14 & 2.28 & -3.41 & 0.36 \\
\hline & 0.86 & 1.17 & -1.14 & 2.28 & -3.43 & 0.36 \\
\hline \multirow[t]{2}{*}{$\mathrm{CO} 3$} & 1.18 & 0.92 & -1.12 & 0.25 & -3.10 & 0.34 \\
\hline & 1.24 & 1.45 & -1.06 & 0.31 & -3.27 & 0.40 \\
\hline \multirow[t]{2}{*}{$\mathrm{CO} 4$} & 0.41 & 0.47 & -1.68 & 2.88 & -3.35 & -0.13 \\
\hline & 0.52 & 0.74 & -1.56 & 2.99 & -3.46 & -0.01 \\
\hline $\cos$ & -0.19 & 0.07 & -2.30 & 1.26 & -4.22 & -0.76 \\
\hline \multirow[t]{2}{*}{ CO6 } & 2.64 & 1.13 & -1.33 & 0.78 & -3.23 & 0.59 \\
\hline & 2.89 & 1.23 & -1.08 & 1.03 & -3.63 & 0.84 \\
\hline \multirow[t]{2}{*}{$\mathrm{CO} 7$} & 1.66 & -0.50 & -1.95 & 3.28 & -3.55 & 0.25 \\
\hline & 1.94 & -0.39 & -1.67 & 3.56 & -3.77 & 0.53 \\
\hline $\mathrm{CO}$ & 0.63 & 1.10 & -1.39 & -0.44 & -3.22 & -0.04 \\
\hline CO9 & 2.35 & 1.05 & -1.31 & 0.39 & -3.55 & 0.43 \\
\hline CO10 & -0.66 & -0.01 & -2.59 & -1.82 & -3.52 & -1.22 \\
\hline CO11 & 1.08 & 0.23 & -2.48 & -1.01 & -3.86 & -0.69 \\
\hline $\mathrm{CO12}$ & -0.25 & 0.32 & -1.97 & -0.92 & -3.63 & -0.52 \\
\hline $\mathrm{CO13}$ & -0.02 & 0.67 & -1.70 & -1.26 & -3.31 & -0.36 \\
\hline $\mathrm{CO14}$ & -2.62 & & & 1.05 & -3.29 & \\
\hline CO15 & 0.30 & & & -2.97 & -3.73 & \\
\hline CO16 & 0.80 & & & 0.86 & -3.67 & \\
\hline
\end{tabular}

${ }^{a}$ Second lines wherever needed.

$\mathrm{X}-\mathrm{H} \cdots \mathrm{Y}$ interactions as more stabilizing than if OCM is applied.

In the case of isodesmic methods, one can observe (Tables 2 and S2 (Supporting Information)) that almost always the interaction energies satisfy the following relation: $E^{\mathrm{IM}}>E^{\mathrm{IM}-\text { long }}$ $\geq E^{\mathrm{IM}-\mathrm{o}} \geq E^{\mathrm{IM}-1}$. This order is a consequence of the sum of $E$ (III) and $E$ (IV) energies in eq 7. This leads to higher energy (i.e., less negative) of $E_{\mathrm{ref}}^{\mathrm{IM}}(\mathrm{I})$ whenever geometries of II, III, and IV are not fully optimized. As a result the value of $E^{\mathrm{IM}}$ (eq 6) becomes lower (i.e., either more negative or less positive).

The fact that estimates of the hydrogen bond strength differ both quantitatively and qualitatively (i.e., even in sign) calls for a grading of the different methods if their use is to be preserved. To this end, we will first consider differences between interaction energies of closely related structures for which a trend could be anticipated in the case of intermolecular hydrogen bonds, and then, we will investigate the quality of the correlation between these interaction energies and $\rho_{\mathrm{b}}$. The first task will be accomplished in this section.

As a first comparison, one can consider $\mathrm{CO} 3$ and $\mathrm{CO} 4$. The presence of $\mathrm{F}$ atoms in the latter system should polarize the $\mathrm{C}-$ 
Table 3. Statistics of the $t$ Test for a Nonrandom Correlation of the Interaction Energy (kcal/mol), $E$, and the Electron Density (a.u.) at the Bond Critical Point of the $\mathrm{H}^{\cdots} \cdots \mathrm{Y}$ Interaction, $\rho_{\mathrm{b}}$, in All Fully Optimized Systems

\begin{tabular}{|c|c|c|c|c|c|c|}
\hline estimate & $\sigma$ & $R^{2}$ & $T$ & $t_{\nu, 0.025}$ & intercept & slope \\
\hline$E^{\mathrm{OCM}}$ & 1.944 & 0.7918 & -9.750 & 2.060 & $5.4 \pm 0.8$ & $-322 \pm 30$ \\
\hline$E^{\mathrm{GCM}}$ & 2.381 & 0.7713 & -8.614 & 2.074 & $5.5 \pm 1.1$ & $-360 \pm 40$ \\
\hline$E^{\mathrm{RRM}}$ & 1.232 & 0.9154 & -15.078 & 2.080 & $3.5 \pm 0.6$ & $-325 \pm 20$ \\
\hline$E^{\mathrm{IM}}$ & 3.181 & 0.7585 & -8.862 & 2.060 & $7.7 \pm 1.4$ & $-480 \pm 50$ \\
\hline$E^{\mathrm{IM}-\text { long }}$ & 3.661 & 0.7659 & -9.045 & 2.060 & $7.7 \pm 1.6$ & $-560 \pm 60$ \\
\hline$E^{\mathrm{IM}-\mathrm{o}}$ & 3.612 & 0.7729 & -9.225 & 2.060 & $7.3 \pm 1.6$ & $-570 \pm 60$ \\
\hline$E^{\mathrm{IM}-1}$ & 3.590 & 0.7744 & -9.264 & 2.060 & $7.2 \pm 1.5$ & $-570 \pm 60$ \\
\hline$E^{\mathrm{EM}}$ & 0.785 & 0.9620 & -25.148 & 2.060 & $2.1 \pm 0.3$ & $-335 \pm 13$ \\
\hline
\end{tabular}

Table 4. Statistics of the $t$ Test for a Nonrandom Correlation of the Interaction Energy (kcal/mol), E, and the Electron Density (a.u.) at the Bond Critical Point of the H*YY Interaction, $\rho_{\mathrm{b}}$, in Fully Optimized CO Systems

\begin{tabular}{|c|c|c|c|c|c|c|}
\hline estimate & $\sigma$ & $R^{2}$ & $T$ & $t_{\nu, 0.025}$ & intercept & slope \\
\hline$E^{\mathrm{OCM}}$ & 1.273 & 0.0178 & -0.504 & 2.145 & $3 \pm 5$ & $-140 \pm 300$ \\
\hline$E^{\mathrm{GCM}}$ & 0.452 & 0.3773 & -2.582 & 2.201 & $4.9 \pm 1.7$ & $-270 \pm 100$ \\
\hline$E^{\mathrm{RRM}}$ & 0.376 & 0.5594 & -3.737 & 2.201 & $3.6 \pm 1.4$ & $-320 \pm 90$ \\
\hline$E^{\mathrm{IM}}$ & 1.916 & 0.1078 & -1.301 & 2.145 & $9 \pm 7$ & $-500 \pm 400$ \\
\hline$E^{\mathrm{IM}-\text { long }}$ & 1.752 & 0.0922 & -1.193 & 2.145 & $7 \pm 6$ & $-500 \pm 400$ \\
\hline$E^{\mathrm{IM}-\mathrm{o}}$ & 1.697 & 0.0715 & -1.039 & 2.145 & $5 \pm 6$ & $-390 \pm 400$ \\
\hline$E^{\mathrm{IM}-1}$ & 1.686 & 0.0693 & -1.021 & 2.145 & $5 \pm 6$ & $-380 \pm 400$ \\
\hline$E^{\mathrm{EM}}$ & 0.032 & 0.9899 & -37.036 & 2.145 & $0.77 \pm 0.12$ & $-261 \pm 7$ \\
\hline$E^{\mathrm{GCRRM}}$ & 0.466 & 0.442 & 2.949 & 2.201 & $5.0 \pm 1.7$ & $-316 \pm 100$ \\
\hline
\end{tabular}

$\mathrm{H}$ bond and, as a consequence, the $\mathrm{C}-\mathrm{H}$... O contact in $\mathrm{CO} 4$ should be either less destabilizing or more stabilizing than in CO3. Indeed, this order is observed in the case of estimates either belonging to the conformational family or based on EM. The opposite order is, however, obtained if isodesmic reactions are considered, namely, a weak hydrogen bond is found in CO3, whereas it is absent in CO4. The same conclusion is obtained if one compares $\mathrm{CO} 3$ with $\mathrm{CO} 5$, i.e. if the $-\mathrm{CH}_{3}$ group is replaced by $-\mathrm{CHCl}_{2}$. Moreover, the substitution of the $-\mathrm{CH}_{3}$ group in $\mathbf{C O} 6$ by $-\mathrm{CHF}_{2}$ in $\mathrm{CO} 7$ leads to the reversal of the interaction character, from weakly stabilizing in $\mathrm{CO6}$ to weakly destabilizing in $\mathrm{CO} 7$ (increase of the destabilizing character in the case of $E^{\mathrm{IM}}$ ), thus the direction of the change of the interaction energy value is again opposite to that found by means of any method from the other two families. Other cases in which the isodesmic family is in almost complete disagreement with the estimates of the other two families arise in the couples $\mathbf{C S 1 - C O 1}$ and $\mathbf{C S 2}-\mathbf{C O} 2$. The substitution of a sulfur by an oxygen as the hydrogen acceptor could be expected to lead to a stronger bonding. Actually, all isodesmic methods and GCM (however, only in the case of fully optimized, i.e. bent structures for which GCM was not anticipated) lead to the opposite conclusion, whereas OCM, RRM, and EM behave as expected.

On the contrary, all methods, including those based on isodesmic reactions, show the expected direction of interaction energy change for the pairs $\mathrm{CO} 8-\mathrm{CO} 10, \mathrm{CO} 8-\mathrm{CO} 12, \mathrm{CO} 8-$ CO13, and CO9-CO11, which are all composed by planar molecules. Thus, it seems that qualitative studies of the influence of substitution effects on the interaction energy value, obtained by means of isodesmic reaction, may be reliable if they concern planar molecules. Nevertheless, even for this subset the agreement of isodesmic and conformational methods is only modest. Indeed, the stronger bond estimated by the isodesmic methods for CO15 when compared with CO16 agrees poorly with the other methods (OCM and EM), where the interaction energy difference among these systems, although of the same sign, is so small to be hardly meaningful. All in all the comparison of interaction energies of closely related compounds seems to disfavor the isodesmic methods.

QTAIM Based Study. The approximate additivity of bond energies indicates that the energy of a chemical bond should be a local quantity determined from a region of the molecular space close to that bond. Methods of the conformational and isodesmic families use two or more values of molecular total energies which are determined by the electron density over the whole molecular space, and it is rather vague whether they can yield such a local quantity. As a clue to the assessment of the local character of an estimate, one can try to correlate the interaction energy with some local property. Among the many properties which can be chosen to accomplish that task, we will focus on the electron density at the bond critical point, $\rho_{\mathrm{b}}$, of the interaction of interest. Indeed, in the case of intermolecular hydrogen and dihydrogen bonds, the standard definition of the hydrogen bond energy as the energy difference of bonded and separated moieties gives linear relationships with $\rho_{\mathrm{b}}{ }^{17,47,72-77,100}$ with slopes ranging from $-142^{47}$ to -358 $\mathrm{kcal} /(\mathrm{mol}$ a.u. $) .^{77}$ No good relationships are known for intramolecular hydrogen bonds-a fact that can be ascribed to both the larger dependence of $\rho_{\mathrm{b}}$ on the molecular fragments ${ }^{71}$ not involved in a hydrogen bond and to the previously discussed difficulty of defining the energy of an intramolecular hydrogen bond.

Using the data reported in Table 2 for interaction energies of fully optimized systems, we observe that EM allows obtaining a good $E$ vs $\rho_{\mathrm{b}}$ correlation $\left(R^{2}=0.962\right.$; see Table 3$)$. This is, however, not an unexpected result since EM (see eq 8) concerns a simple proportionality between the interaction energy and the electronic potential energy density, $V_{\mathrm{b}}$-a local property that is known to correlate with $\rho_{\mathrm{b}} \cdot{ }^{101}$ Moreover, for small ranges of $\rho_{\mathrm{b}}$ (and $E$ ) this proportionality can be treated as linear. All other methods discussed here give considerably 


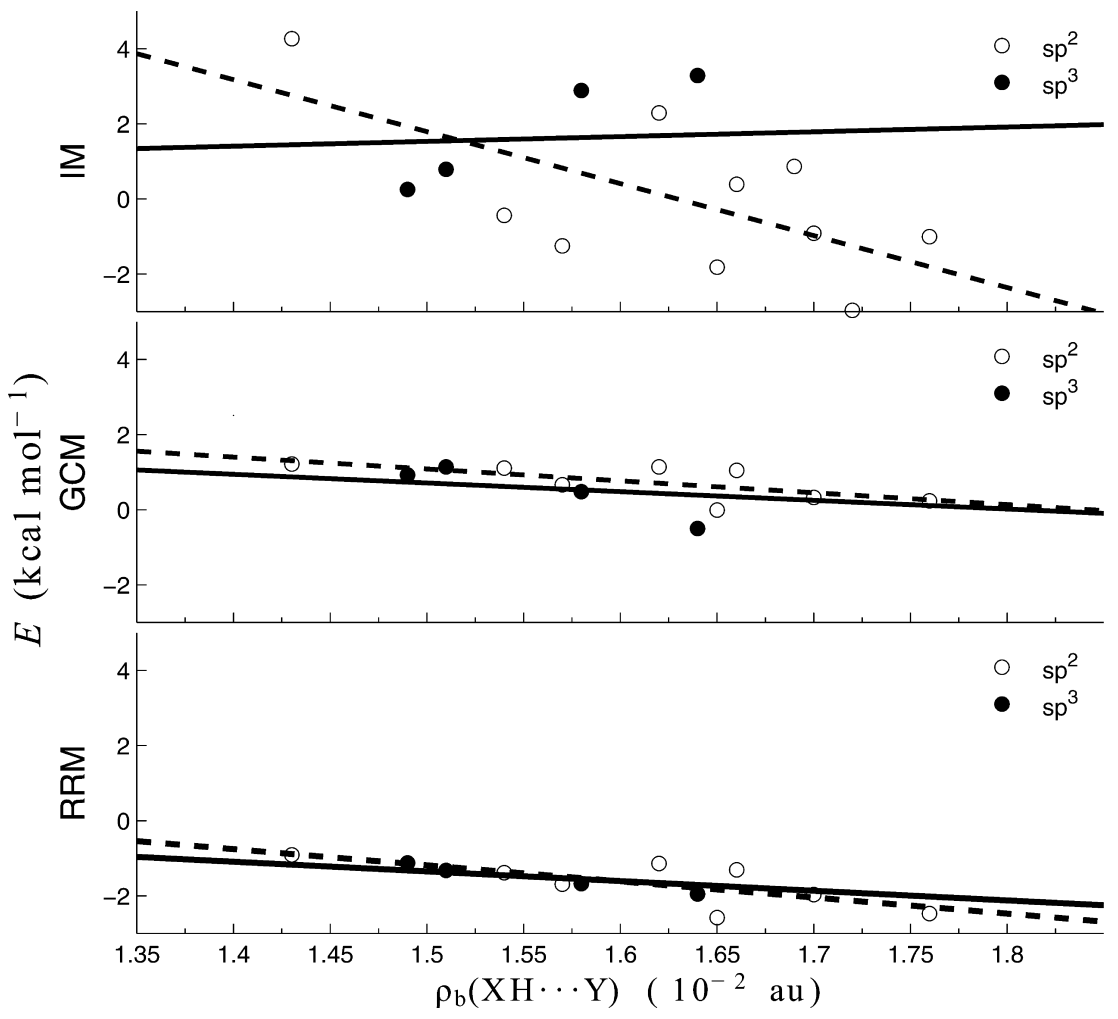

Figure 4. Correlation of $\mathrm{CH} \cdots \mathrm{O}$ interaction energies estimated by three different methods with the electron density at the bond critical point of that interaction. For each of the three methods IM, GCM, and RRM, data with C-H carbon in either $\mathrm{sp}^{2}$ (empty marks) or sp ${ }^{3}$ (full marks) hybridization are reported and trendlines determined from them are plotted with the dashed and continuous line, respectively.

poorer $E$ vs $\rho_{\mathrm{b}}$ correlations $\left(R^{2}\right.$ ranging from 0.759 for IM to 0.915 for RRM). Although all correlations are statistically significant (they pass a two-tail $t$ test at the $95 \%$ confidence level), the poorest correlations obtained with the isodesmic methods are associated with slopes which fall outside the range reported for dimers, ${ }^{74,75}$ whereas all conformational methods and EM have slopes in the range of -360 to $-322 \mathrm{kcal} /(\mathrm{mol}$ a.u.), thus overlapping the previously reported slopes for dimers. 74,75

In addition with the considerably poorer quality of the linear fits, a further difference with the intermolecular case is that the overall linear correlations considerably worsen upon selecting a subclass of hydrogen bonded systems (with the single exception of EM). This result seems to be somewhat unexpected.

In the following, we focus on the more abundant $\mathbf{C O}$ systems (Table 4). The only methods leading to correlations (significant at the $95 \%$ confidence level) between estimated interaction energies and the electron density at the bond critical point $\left(\rho_{\mathrm{b}}\right)$ of the $\mathrm{C}-\mathrm{H} \cdots \mathrm{O}$ interaction are GCM, RRM, and EM. Moreover, for these three methods only, the slopes are close to each other and also close to those for hydrogenbonded dimers. $^{74,75}$

Upon further considering subsets with $\mathrm{sp}^{2}$ and $\mathrm{sp}^{3}$ hybridization at carbon (see Tables S3 and S4, respectively, in the Supporting Information), RRM and EM still give significant correlations (i.e., $|T|>t_{\nu, 0.025}$ ) between $E$ and $\rho_{\mathrm{b}}$ for both subsets (however, $R^{2}$ for RRM is still poor, being 0.510 and 0.857 for $\mathrm{sp}^{2}$ and $\mathrm{sp}^{3}$ subsets, respectively), whereas OCM grossly fails for both subsets. GCM and IM have an intermediate behavior: GCM fails for the $\mathrm{sp}^{3}$ subset and has only a marginal failure for the $\operatorname{sp}^{2}$ subset $\left(|T|=2.25, t_{\nu, 0.025}=\right.$
2.45); IM grossly fails for the $\mathrm{sp}^{3}$ subset and passes the test for the $\mathrm{sp}^{2}$ subset. The better performance of GCM and IM in the case of the $\mathrm{sp}^{2}$ subset, as compared with $\mathrm{sp}^{3}$, can be understood because all $\mathrm{sp}^{3}$ systems (but CO5) are bent. This implies that the reference energies of these systems are less reliable. Actually, this observation should also be done for RRM, but in that case the correlation is statistically significant for both subsets (Tables S3 and S4 in the Supporting Information).

The nonoptimal performance of GCM and IM in the correlations with $\rho_{\mathrm{b}}$ can be further discussed considering the slopes. For GCM, the slopes obtained in both these cases $(-320 \pm 140$ and $-230 \pm 180 \mathrm{kcal} /(\mathrm{mol}$ a.u. $))$ are poorly defined but close to each other and, moreover, close to the slopes reported for hydrogen-bonded dimers. ${ }^{74,75}$ On the other hand, for IM the slopes, in addition to being poorly defined $(-1400 \pm 600$ and $100 \pm 400 \mathrm{kcal} /(\mathrm{mol}$ a.u. $))$, differ considerably from the dimer estimates. Indeed, the slope obtained for the $\mathrm{sp}^{3}$ subset, where the $t$ test was not passed, even assumes an unphysical positive value (see Figure 4). Notably, although the variants of IM, i.e. IM-1, IM-o, and IM-long, give better $E / \rho_{\mathrm{b}}$ correlations considering all the molecules (Table 3 ), which seems to be an indication in their favor, focusing on the subset of $\mathbf{C O}$ molecules, the variants perform statistically worse than IM, which itself does not lead to a significant $E / \rho_{\mathrm{b}}$ correlation (Table 4 ). Thus, once again, GCM is preferred over IM.

Grading of Conformational Methods. The statistically significant correlations between the interaction energy and $\rho_{\mathrm{b}}$ obtained for GCM, RRM, and EM, together with their dimerlike slopes and their reasonable performance in the comparison of interaction energies obtained for closely related systems strengthen our confidence in these methods. It should 
be recognized that although the good $E^{\mathrm{EM}}$ vs $\rho_{\mathrm{b}}$ correlation could have been somewhat anticipated, because EM (see eq 8 ) uses a local quantity to estimate the interaction energy, this is not the case for GCM and RRM, which both use combinations of conformer energies. However, these methods give opposing conclusions for the nature of the $\mathrm{C}-\mathrm{H} \cdots \mathrm{O}$ interaction: RRM estimates are always stabilizing, while those based on GCM are almost always destabilizing (with the exception of $\mathrm{CO} 7$ and CO10). The reasonably large subset of $\mathrm{CO}$ systems for which RRM and GCM could be applied, i.e. systems CO1-CO13, allows a deeper examination of the difference between these two methods. The $E^{\mathrm{GCM}}-E^{\mathrm{RRM}}$ interaction energy difference has a fairly constant positive value of $2.3 \pm 0.3 \mathrm{kcal} / \mathrm{mol}$ and qualifies well as a difference of zero of interaction energy. Therefore, the source of the qualitative disagreement on the stabilizing/destabilizing nature of most of the studied $\mathrm{C}-\mathrm{H} \cdots \mathrm{O}$ interactions comes from a different zero of the interaction energy, and this prompts us to reexamine the basic assumptions of GCM and RRM in an attempt to grade the soundness of their zeroes of interaction energy.

The reference energy adopted by GCM does not include the CCT conformation (eq 3), on the basis that it contains a close (destabilizing) $\mathrm{H} \cdot \cdots \mathrm{H}$ contact. That contribution appears with a negative sign in RRM and, as a consequence, the first term in eq 5 and the whole $E^{\mathrm{RRM}}$ should be too negative. From this point of view, RRM is expected to give an inappropriately low (too much stabilizing) value for the $\mathrm{C}-\mathrm{H} \cdots \mathrm{O}$ interaction. On the other hand, RRM is consistent with the ansatz that each bond gives an additive contribution to the molecular energy and that contribution differs for different dihedral angles. Considering the higher total energy (i.e., less negative) of cis-2butene and s-cis-butadiene compared with their trans forms, $\mathrm{C}$ bonds on the middle and rightmost bond of the conformations depicted in Figure 2 can be expected to bring an energy penalty with respect to $\mathrm{T}$ bonds and, as a consequence, they should lead to less stabilized systems. From this perspective, GCM, requiring subtraction of only $1 / 2 \mathrm{C}$ terms from $2 \mathrm{C}$ terms (eqs 2 and 3), can be expected to give an inappropriately high (too much destabilizing) value for the $\mathrm{C}-\mathrm{H} \cdots \mathrm{O}$ interaction. The direct comparison of these two methods is further complicated by the fact that energies of CTC and CTT conformations in GCM are computed for the nonoptimized geometries, CTC $_{\mathrm{CCC}}$ and $\mathrm{CTT}_{\mathrm{CCC}}$, respectively, i.e. the nonequilibrium geometries with all internal coordinates-but of course main chain dihedral(s) - taken from the CCC conformer. In order to further investigate the matter, the energy difference is written as

$$
\begin{aligned}
E^{\mathrm{GCM}}-E^{\mathrm{RRM}}= & \frac{1}{2}\left[E(\mathrm{CTC})-\mathrm{E}\left(\mathrm{CTC}_{\mathrm{CCC}}\right)\right] \\
& +\frac{1}{2}\left[E(\mathrm{CTT})-\mathrm{E}\left(\mathrm{CTT}_{\mathrm{CCC}}\right)\right] \\
& +\frac{1}{2}[E(\mathrm{CTC})-\mathrm{E}(\mathrm{CTT})] \\
& +[E(\mathrm{CCT})-\mathrm{E}(\mathrm{CTT})]
\end{aligned}
$$

showing that the difference of the two estimates results from a balance between relaxation energies of nonoptimized conformers $\left(\mathrm{CTC}_{\mathrm{CCC}} \rightarrow \mathrm{CTC}\right.$ and $\mathrm{CTT}_{\mathrm{CCC}} \rightarrow \mathrm{CTT}$, the first two terms) and energies of conformational isomerization (CTT $\rightarrow$ $\mathrm{CTC}$ and $\mathrm{CTT} \rightarrow \mathrm{CCT}$, the last two terms). As seen from Table 5, these contributions have opposite signs, but absolute values of relaxation energies are smaller than energy values that correspond to the $\mathrm{T} \rightarrow \mathrm{C}$ conformational changes. Moreover,
Table 5. Energies (in $\mathrm{kcal} / \mathrm{mol}$ ) of Conformational Switch for Diverse Fully Optimized CO Systems, Acrolein, and 2Butene

\begin{tabular}{llc} 
system $(\mathrm{s})$ & \multicolumn{1}{c}{ process } & $\Delta E \pm \sigma(\Delta E)$ \\
CO1-CO13 & $E^{\mathrm{GCM}}-E^{\mathrm{RRM}}$ & $2.3 \pm 0.3$ \\
CO1-CO13 & $\mathrm{CTC}_{\mathrm{CCC}} \rightarrow \mathrm{CTC}$ & $-1.3 \pm 0.3$ \\
CO1-CO13 & $\mathrm{CTT}_{\mathrm{CCC}} \rightarrow \mathrm{CTT}$ & $-2.0 \pm 0.6$ \\
CO1-CO13 & $\mathrm{CTT} \rightarrow \mathrm{CTC}$ & $2.5 \pm 0.8$ \\
CO1-CO13 & $\mathrm{CTT} \rightarrow \mathrm{CCT}$ & $2.7 \pm 0.3$ \\
CO1-CO13 & $\mathrm{CTT} \rightarrow \mathrm{CTT}_{\mathrm{CCT}}$ & $1.0 \pm 0.2$ \\
CO1-CO13 & $\mathrm{CTT} \rightarrow \mathrm{CTT}_{\mathrm{CTC}}$ & $0.18 \pm 0.08$ \\
acrolein & $\mathrm{T} \rightarrow \mathrm{C}$ & 2.26 \\
acrolein & $\mathrm{T} \rightarrow \mathrm{T}_{\mathrm{C}}$ & 0.15 \\
2-butene & $\mathrm{T} \rightarrow \mathrm{C}$ & 1.04 \\
2-butene & $\mathrm{T} \rightarrow \mathrm{T}_{\mathrm{C}}$ & 0.43 \\
\hline
\end{tabular}

the last term in eq 10 contributes without the factor $1 / 2$ as all other terms. As a consequence, the energetic difference between GCM and RRM (eq 10) assumes a positive value. If taken individually, the terms in square brackets of eq 10 have a greater spread than the whole difference (Table 5), but they give some insight in the transferability of the rotational contribution to the energy. Indeed, the energy needed for the $\mathrm{CTT} \rightarrow$ CTC isomerization in CO systems $(2.5 \pm 0.8 \mathrm{kcal} /$ $\mathrm{mol})$ is close to the value $(2.26 \mathrm{kcal} / \mathrm{mol})$ computed for the $\mathrm{T}$ $\rightarrow \mathrm{C}$ change in acrolein $\left(\mathrm{CH}_{2}=\mathrm{CH}-\mathrm{CHO}\right)$. No such transferability of the dihedral contribution to the molecular energy is found for the central double bond: the CTT $\rightarrow$ CCT process has an average value of $2.7 \pm 0.3 \mathrm{kcal} / \mathrm{mol}$ for $\mathbf{C O}$ systems and a considerably lower value $(1.04 \mathrm{kcal} / \mathrm{mol})$ for 2 butene. This nontransferability puts some limits to RRM and is a central point in the analysis of the difference between GCM and RRM given by eq 10 . In effect, the energy of the CTT $\rightarrow$ $\mathrm{CCT}$ process, when averaged over $\mathrm{CO}$ systems, is close to the whole difference $E^{\mathrm{GCM}}-E^{\mathrm{RRM}}$, while the first three strongly correlated terms of eq 10 average to a small value of $-0.4 \pm 0.3$ $\mathrm{kcal} / \mathrm{mol}$. Therefore, the origin of the $E^{\mathrm{GCM}}-E^{\mathrm{RRM}}$ difference can be understood considering the energy change in the single $\mathrm{CTT} \rightarrow \mathrm{CCT}$ isomerization. From the standpoint of GCM that change is determined by the $\mathrm{H} \cdots \mathrm{H}$ repulsion and does not appear in the estimate of the $\mathrm{C}-\mathrm{H} \cdots \mathrm{O}$ interaction energy, while from the standpoint of RRM that difference is determined by an additive dihedral-dependent bond contribution, transferable among conformers, and appears in the definition of the $\mathrm{C}-$ $\mathrm{H} \cdots \mathrm{O}$ interaction energy.

We have already noticed that the assumption of transferability is troublesome in the case of the central bond of $\mathbf{C O}$ systems: the average energy for the CTT $\rightarrow$ CCT transformation exceeds the energy of the $\mathrm{T} \rightarrow \mathrm{C}$ transformation in 2-butene by roughly $1.7 \mathrm{kcal} / \mathrm{mol}$ (Table 5). Therefore, it is tempting to interpret this lack of transferability in terms of the additional $\mathrm{H} \cdots \mathrm{H}$ repulsion occurring in the CCT conformation. To better ascertain such nontransferability, we found expedient to decompose the conformational isomerization in a geometrical preparation step followed by a rigid-rotor isomerization

$$
\mathrm{CTT} \rightarrow \mathrm{CTT}_{\mathrm{CCT}} \rightarrow \mathrm{CCT}
$$




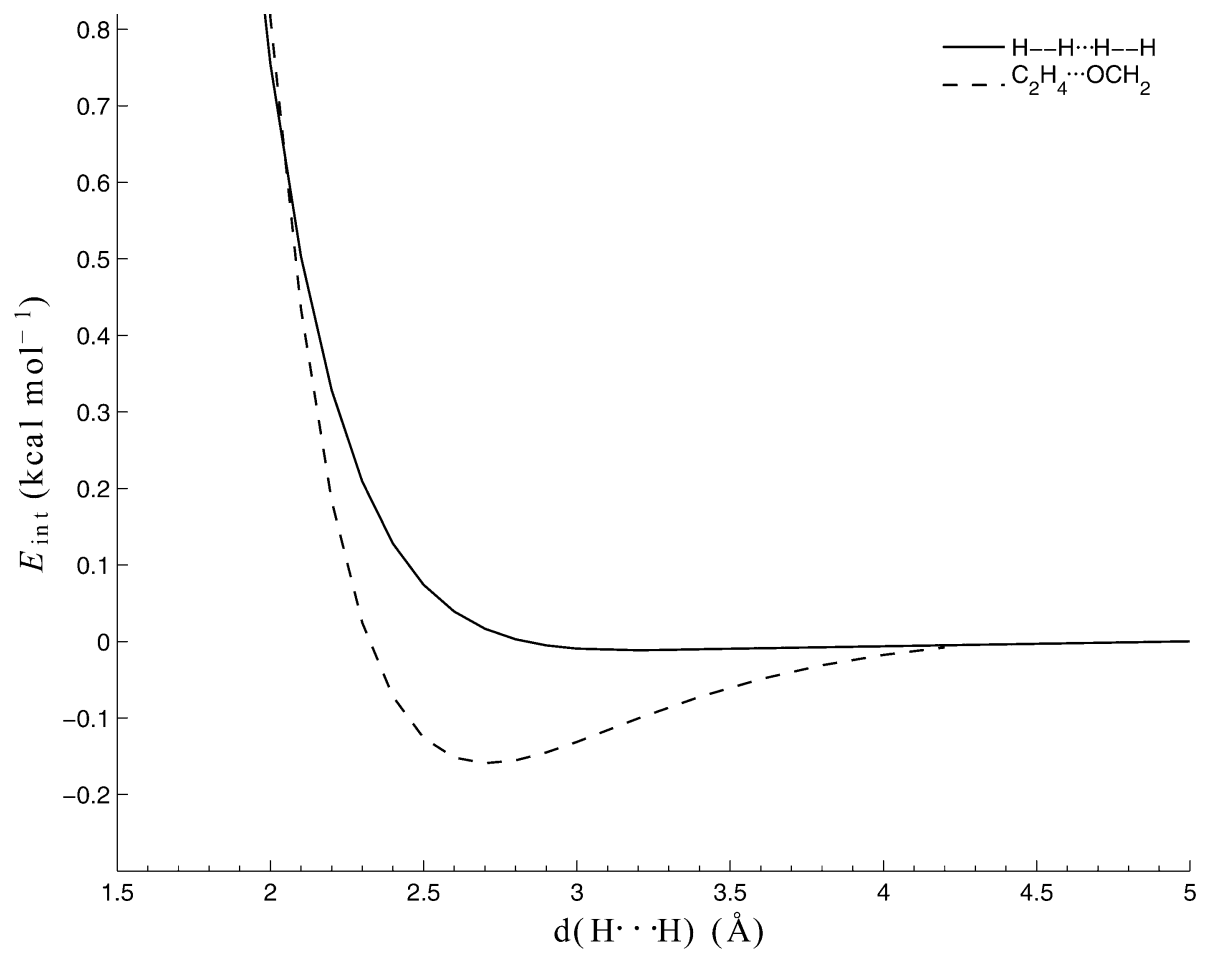

Figure 5. Energy of the linear $\mathrm{H}-\mathrm{H} \cdots \mathrm{H}-\mathrm{H}$ and ethylene $\cdots$ formaldehyde (oriented as in Figure 6) dimers as a function of the $\mathrm{H} \cdots \mathrm{H}$ distance. Points have been obtained by counterpoise correction of MP2/aug-cc-pVTZ calculations.

$$
\begin{aligned}
E(\mathrm{CCT})-E(\mathrm{CTT}) \\
=\left[E\left(\mathrm{CTT}_{\mathrm{CCT}}\right)-E(\mathrm{CTT})\right]+[E(\mathrm{CCT}) \\
\left.\quad-E\left(\mathrm{CTT}_{\mathrm{CCT}}\right)\right]
\end{aligned}
$$

A similar decomposition is applicable to any conformational isomerization. Using this decomposition one gets that for the $\mathrm{CTT} \rightarrow$ CTC process the energy contribution due to the geometrical preparation step $\left(\mathrm{CTT} \rightarrow \mathrm{CTT}_{\mathrm{CTC}}\right)$ is very modest $(0.18 \pm 0.08 \mathrm{kcal} / \mathrm{mol})$ and a closely small effect is computed for the similar $\mathrm{T} \rightarrow \mathrm{T}_{\mathrm{C}}$ process in acrolein $(0.15 \mathrm{kcal} / \mathrm{mol})$. However, the energy change in the CTT $\rightarrow \mathrm{CTT}_{\mathrm{CCT}}$ process averaged over the same subset is as high as $1.0 \pm 0.2 \mathrm{kcal} / \mathrm{mol}$, which is a considerable fraction (37\%) of the overall energy change in the conformational isomerization $(2.7 \pm 0.3 \mathrm{kcal} /$ $\mathrm{mol})$. A similarly large percentual contribution of the energy change is obtained for the $\mathrm{T} \rightarrow \mathrm{T}_{\mathrm{C}}$ step in 2-butene $(0.43 \mathrm{kcal} /$ mol, i.e. $41 \%)$. Therefore, nontransferable bond contributions are also associated with a larger geometry change. If we accept that this geometry change and the resulting energy increase are totally due to the effort to escape the close $\mathrm{H} \cdots \mathrm{H}$ contacts $(2.06$ $\AA \AA$ in the $\mathrm{C}$ conformer of 2-butene and 2.00-2.14 $\AA$ in the CCT conformers of CO systems), we can say that the RRM hydrogen bond estimate is too much stabilizing by roughly 1 $\mathrm{kcal} / \mathrm{mol}$.

On the other hand the rigid-rotor isomerization $\mathrm{CTT}_{\mathrm{CCT}} \rightarrow$ CCT is also influenced by the $\mathrm{H} \cdots \mathrm{H}$ repulsion. To estimate the amount of this contribution, we considered a pair of $\mathrm{H}_{2}$ molecules arranged linearly. We optimized the geometry of the dimer for a set of intermolecular $\mathrm{H} \cdots \mathrm{H}$ distances, and then, we computed the interaction energy after applying the basis set superposition correction. ${ }^{102}$ The results are displayed in Figure 5. At distances found in CCT conformers (2.00-2.14 $\AA$ ), the repulsion of the two hydrogens, estimated from the $\mathrm{H}_{2}$ dimer model, ranges from 0.76 to $0.43 \mathrm{kcal} / \mathrm{mol}$. On consideration that a proper dimer model should take the polarity of the $\mathrm{C}-\mathrm{H}$ bond into account, the guess of the $\mathrm{H} \cdots \mathrm{H}$ repulsion, based on the $\mathrm{H}_{2} \cdots \mathrm{H}_{2}$ dimer model, may seem to be too simplified. Nevertheless it gives the first estimate of the order of the $\mathrm{H} \cdots \mathrm{H}$ repulsion energy in CCT conformers of investigated systems.

It is not easy to have estimations based on a dimer model that would more closely resemble the interacting units in our molecules because with larger molecules the interaction energy would be strongly influenced by electrostatic interactions. ${ }^{18,66}$ Nevertheless, we also considered the dimer ethylene $\cdots$ formaldehyde (which could be a model of the $\mathrm{H} \cdots \mathrm{H}$ interaction in CO8 and CO9), on the account that ethylene is apolar. The orientation of the two molecules was fixed in a plane with an all-trans arrangement of the $\mathrm{C}=\mathrm{C}-\mathrm{H} \cdots \mathrm{H}-\mathrm{C}=\mathrm{O}$ moiety and bending angles fixed to preserve the parallelism of $\mathrm{C}=\mathrm{C}$, $\mathrm{H} \cdots \mathrm{H}$, and $\mathrm{C}=\mathrm{O}$. This orientation prevents close contacts of two pairs of $\mathrm{H}$ atoms rather than a single pair (see Figure 6). The association energy was computed as above for the $\mathrm{H}_{2}$ dimer. Results are also shown in Figure 5. It can be noticed that at distances close to those encountered in the CCT conformers, the association energies of the $\mathrm{H}-\mathrm{H} \cdots \mathrm{H}-\mathrm{H}$ and ethyl-
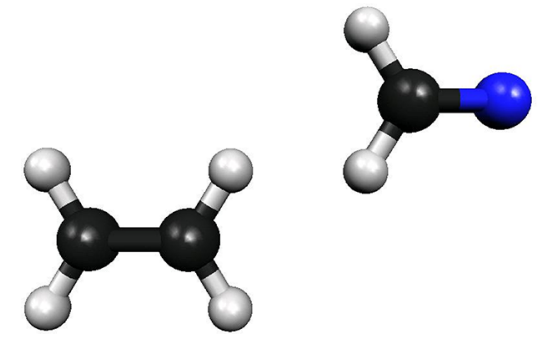

Figure 6. Arrangement of the ethylene $\cdots$ formaldehyde dimer used to estimate the $\mathrm{H} \cdots \mathrm{H}$ repulsion energy. 


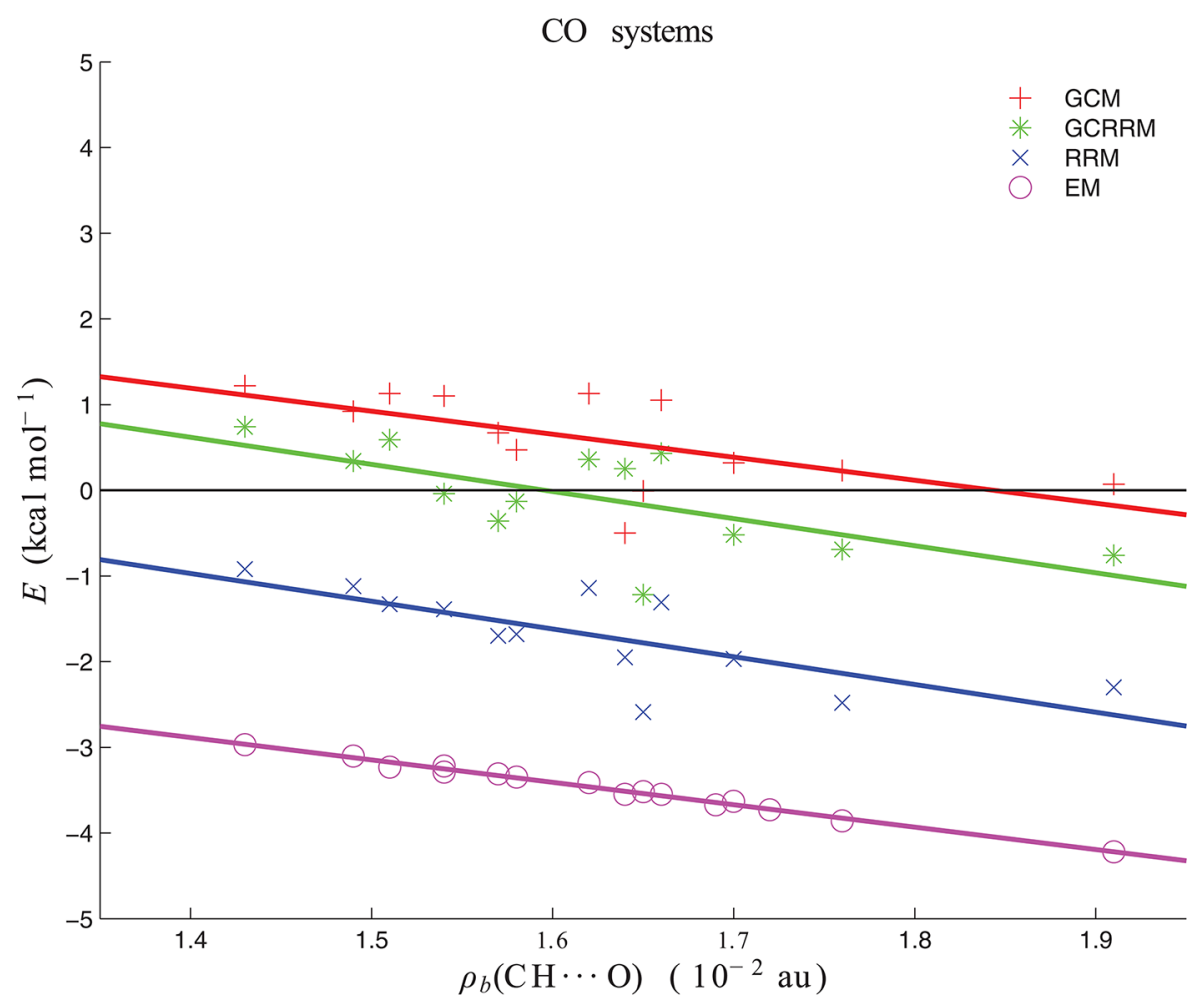

Figure 7. $\mathrm{CH} \cdots \mathrm{O}$ interaction energies estimated by GCM, GCRRM, RRM, and EM vs the electron density at the bond critical point of the interaction.

ene $\cdots$ formaldehyde dimer models are rather close to each other. This gives us some confidence in using the $\mathrm{H}-\mathrm{H} \cdots \mathrm{H}-\mathrm{H}$ potential to estimate the $\mathrm{H} \cdots \mathrm{H}$ repulsion energy in CCT forms of our CO systems. However, rather than using the detailed potential, we prefer to introduce the single median value of 0.6 $\mathrm{kcal} / \mathrm{mol}$, taking into account that a spread of at least $0.17 \mathrm{kcal} /$ mol can be expected; indeed, small changes in geometry can be expected to bring considerable changes in the repulsion energy according to the large slope of the energy curve.

Eventually, considering the energies just estimated for the geometrical preparation step $(1.0 \pm 0.2 \mathrm{kcal} / \mathrm{mol})$ and the $\mathrm{H} \cdots \mathrm{H}$ repulsion energy estimated for CCT conformations $(0.60 \pm 0.17 \mathrm{kcal} / \mathrm{mol})$, we can expect that the CTT $\rightarrow$ CCT process is affected by close contacts by roughly $1.6 \mathrm{kcal} / \mathrm{mol}-\mathrm{a}$ value being virtually the difference between the energy of the $\mathrm{CTT} \rightarrow \mathrm{CCT}$ isomerization of $\mathrm{CO}$ systems $(2.7 \mathrm{kcal} / \mathrm{mol})$ and the energy of the $\mathrm{T} \rightarrow \mathrm{C}$ isomerization in 2-butene $(1.04 \mathrm{kcal} /$ $\mathrm{mol}$ ). This nice agreement leads us to an improved conformational method, named the geometry corrected related rotamers method (GCRRM), with interaction energies given by

$$
E^{\mathrm{GCRRM}}=E^{\mathrm{RRM}}+\left[E\left(\mathrm{CTT}_{\mathrm{CCT}}\right)-E(\mathrm{CTT})\right]+E_{\mathrm{HH}}
$$

where $\mathrm{E}_{\mathrm{HH}}$ is $0.6 \mathrm{kcal} / \mathrm{mol}$. Interaction energies computed according to this novel method are scattered closer to either GCM or RRM, but in the case of CO systems only, they are almost systematically intermediate between the two methods and always closer to GCM (see Table 2 and Figure 7).

The changes induced by the adoption of GCRRM can be appreciated considering the correlation between the estimated interaction energy and the geometry of the CCC conformations. Minimum energy twisted structures are expected to result from the destabilizing interaction between close ends of the
CCC conformer (see the SI for a calculation on dimers). ${ }^{28,59}$ This does not rule out repulsive interactions for planar systems, where the loss of the repulsion with the twist angle can be just insufficient to overweight the increase of energy expected for the out-of-plane distortion of the hypothetical molecule devoid of the $\mathrm{CH} \cdots \mathrm{O}$ interaction. Destabilizing interactions are predicted by GCM for almost all CO systems, the only nonnegligible negative interaction is estimated for the nonplanar CO7. There is a poorly defined tendency of twisted/planar structures to be associated with higher/lower repulsion energies. On the other hand, stabilizing $\mathrm{CH} \cdots \mathrm{O}$ interactions (as predicted by EM and RRM) are highly compatible with planar structures, but they could be acceptable for twisted structures only if the attractive interaction would be compensated by additional energetic terms, as could be computed within the IQA approach.

As a matter of fact, the positive/negative values of $E^{\mathrm{GCM}}$ and $E^{\mathrm{RRM}}$ are associated with a twisted/planar structure for the optimized CCC conformer only 6 and 7 times, respectively, over 13 cases. The positive/negative energies of GCRRM, on the other hand, are associated with twisted/planar structures of optimized CCC conformers 11 times out of 13, the only exceptions being $\mathrm{CO} 4$ and CO9. Actually the energy estimate for CO4 is so small to be hardly meaningful.

Different Zeroes of Interaction Energies for Valuable Methods. As it is apparent from Figure 7, all four methods GCM, GCRRM, RRM, and EM have close slopes. This means that the main difference among all of them is their zero of the interaction energy. Actually, this turns out to be true within a small standard error $s=0.4-0.5 \mathrm{kcal} / \mathrm{mol}\left(E^{\mathrm{GCM}}=E^{\mathrm{EM}}+4.0\right.$ $\mathrm{kcal} / \mathrm{mol}, E^{\mathrm{GCRRM}}=E^{\mathrm{EM}}+3.4 \mathrm{kcal} / \mathrm{mol}$, and $E^{\mathrm{RRM}}=E^{\mathrm{EM}}+1.7$ $\mathrm{kcal} / \mathrm{mol}$ ). It is thus clear that the stabilizing/destabilizing nature of the $\mathrm{C}-\mathrm{H} \cdots \mathrm{O}$ interaction is determined by the zero of 
the interaction energy. The interpretative power of Figure 7 should not be underestimated. First of all, we notice that an increase of the electron density at the BCP leads to a larger stabilization not only in EM but also in GCM, GCRRM, and RRM, which are methods based on total energies of conformers, not on single-molecule energy partitions. This indicates that all methods are effective in identifying a local contribution to the energy. Indeed, according to Berlin's theorem for diatomic molecules, ${ }^{103}$ the electron density between the nuclei (where the BCP is found) gives a binding contribution and the increase of internuclear electron density is expected to give a stronger binding contribution. This general argument, applicable to any pairwise interaction, is insufficient to assess that $\mathrm{CH} \cdots \mathrm{O}$ interactions are overall stabilizing with respect to a situation in which there are no such interactions. Indeed, the interacting moieties have to be changed in order to interact, and the change they undergo may well lead to an energy increase high enough to overcome the binding interaction. This is the case of CS systems, where most methods using reference systems (or even all in the case of CS1) estimate a destabilization, which is consistent with the most legible twisting of both ends of the CCC conformer (see Table 1) as well as with both the shortening of the $\mathrm{C}-\mathrm{H}$ bond and the blue shift of its stretching vibration frequency. ${ }^{68}$ That destabilization is still consistent with the local binding contribution between hydrogen and sulfur expected by Berlin's theorem, provided that one considers that interacting moieties are to be strongly perturbed by the formation of the bonding interaction itself. This is best discussed considering EM, which was proposed ${ }^{41}$ for intermolecular hydrogen bonds and consists in a linear relationship between dissociation energies and potential energy density at the bond critical point, with no intercept (eq 8). The absence of an intercept in EM is physically sound because density and potential energy density go to zero as long as two units are pulled apart. This is not the case for intramolecular hydrogen bonds, where it is not possible to pull apart the interacting units without destroying the system. The only possibility to have a zero density at the bond critical point is to constrain electrons on the interacting units, leading, as a consequence, to the increase of the total energy of a system. This could be accounted by the following extension of EM:

$$
E^{\mathrm{EM}-\text { intra }}=E^{\mathrm{EM}}+k
$$

Although an energy increase, $k$, due to the formation of an intramolecular interaction with a zero value for $\rho_{\mathrm{b}}$ could be easily accepted, the estimation of its amount is cumbersome. Indeed, different values of zeroes of interaction energies, obtained by means of investigated methods, lead to its different value. All these methods are acceptable if one focuses on their $E / \rho_{\mathrm{b}}$ slopes, but the arguments given in the previous sections lead us to prefer GCRRM, introduced to overcome conceptual limitations of RRM and GCM. As reported above, for CO systems GCRRM and EM give energies that differ by a constant and the value of $k$ should be $3.4 \mathrm{kcal} / \mathrm{mol}$.

Although conclusions presented here were obtained for a specific group of $\mathbf{C O}$ systems, all with a six-membered quasiring, it is not clear whether they can be used also for other systems. Other $\mathbf{C O}$ systems may be characterized by different range of $\mathrm{H} \cdots \mathrm{H}$ distances in their CCT conformers. More general $\mathrm{X}-\mathrm{H} \cdots \mathrm{Y}$ interactions may also lead to different polarities of $\mathrm{X}-\mathrm{H}$ bonds and, as a consequence, to different estimations of either the $E_{\mathrm{HH}}$ term (as well as the second one) in eq 13 or the $k$ value in eq 14 . On the other hand, the idea of receiving either $E^{\mathrm{GCRRM}}$ (eq 13 ) or $E^{\mathrm{EM}-\text { intra }}$ (eq 14) seems, however, not to be influenced.

\section{CONCLUSIONS}

We have investigated 27 molecules based on quasi-cyclic sixmembered ring and possessing an intramolecular $\mathrm{X}-\mathrm{H} \cdots \mathrm{Y}$ interaction. Particular attention has been devoted to $\mathbf{C O}$ systems with $\mathrm{C}-\mathrm{H} \cdots \mathrm{O}$ contact. We have first adopted eight different methods for estimating energies of these intramolecular interactions: three conformational methods, four isodesmic methods, and Espinosa's method (EM). A wide range of results is obtained with these different methods, and in the case of $\mathbf{C O}$ systems, the sign itself of the interaction energy can change upon changing the method. Values of interaction energies obtained by means of isodesmic reactions seem to be more reliable if they concern planar molecules; otherwise, comparison of values obtained for chemically close systems may be in disagreement with trends expected from the intermolecular analogies. Among the conformational methods, RRM and OCM generally lead to the strongest and weakest stabilization, respectively, while GCM has an intermediate behavior.

By comparison of trends expected for chemically close systems, correlations with the electron density at the bond critical point, $\rho_{\mathrm{b}}$, and comparison of the slopes of the $E / \rho_{\mathrm{b}}$ relations with those already known for intermolecular cases, we could select methods GCM, RRM, and EM as the best performing ones. Interaction energies obtained by means of RRM and GCM significantly correlate with $\rho_{\mathrm{b}}$ yielding slopes comparable to the intermolecular case and indicating that these methods are effective in extracting a local energy from a combination of molecular total energies.

A detailed investigation of the difference between RRM and GCM has led us to propose a novel method, named GCRRM. In the case of $\mathbf{C O}$ systems, this method gives interaction energy values which are almost systematically intermediate between those obtained by means of RRM and GCM. Eventually all methods EM, GCM, RRM, and GCRRM have close slopes and mostly differ by their zero of the interaction energy (Figure 7). The negative slopes indicate that an accumulation of charge in the space separating $\mathrm{CH}$ and $\mathrm{O}$ moieties of $\mathrm{CO}$ systems leads to a stabilization, in close analogy with Berlin's theorem for diatomic molecules. ${ }^{103}$ However, this is insufficient to state that all $\mathrm{CH} \cdots \mathrm{O}$ interactions are overall stabilizing. Indeed, referring at Figure 7 , although all methods share a common $E / \rho_{\mathrm{b}}$ slope, they have a different zero of the interaction energy. This zero value increases along the series EM, RRM, GCRRM, GCM, and as a consequence, fewer and fewer systems are predicted to have a stabilizing $\mathrm{CH} \cdots \mathrm{O}$ interaction.

GCRRM is believed to be the best method because it has been introduced to overcome limitations of RRM and GCM. For this method, the interaction energies are on average 3.4 $\mathrm{kcal} / \mathrm{mol}$ higher than those computed by EM. The introduction of a constant $k$ in EM can thus be used to retrieve the values of GCRRM (eq 14). The extension of EM to the intramolecular case should be well applied to other intramolecular interactions, after determination of the system-dependent intercept $k$.

\section{ASSOCIATED CONTENT}

\section{S Supporting Information}

Table showing the total energy increase caused by forced planar

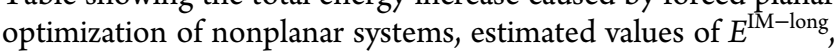


$E^{\mathrm{IM}-\mathrm{o}}$, and $E^{\mathrm{IM}-1}$ for the $\mathrm{X}-\mathrm{H} \cdots \mathrm{Y}$ contact in fully optimized and planarized closed forms, tables showing statistics of the $t$ test for correlations between $E$ and $\rho_{\mathrm{b}}$ for $\mathrm{sp}^{2}$ and $\mathrm{sp}^{3}$ subsets of $\mathrm{CO}$ systems, table listing values of QTAIM parameters calculated at the bond critical point of the $\mathrm{H} \cdots \mathrm{Y}$ interaction in fully optimized and planar forms of investigated systems, figure showing the model propene $\cdots$ formaldehyde dimer built on the framework of planarized CO3 system, and table showing the $\mathrm{CP}$-corrected interaction energies of this dimer as depending on the rotation angle of the $-\mathrm{CH}_{3}$ group of propene. This material is available free of charge via the Internet at http:// pubs.acs.org.

\section{AUTHOR INFORMATION}

\section{Corresponding Author}

*E-mail: teojab@chem.uni.torun.pl (M.J.); gmonaco@unisa.it (G.M.). Phone: +48 (56) 6114695. Fax: +48 (56) 6542477.

\section{Notes}

The authors declare no competing financial interest.

\section{ACKNOWLEDGMENTS}

Calculations have been carried out on the CINECA's SP6 system thanks to the Project HPC-Europa2 (Project number 228398), with the support of the European Communityunder the FP7 "Research Infrastructures" Programme.

\section{REFERENCES}

(1) Marsh, R. E. Structural Chemistry and Molecular Biology; W. H. Freeman: San Francisco, 1968.

(2) Hamilton, W. C.; Ibers, J. A. Hydrogen Bonding In Solids; W. A. Benjamin: New York, 1968.

(3) Nowak, A. Structure and Bonding; Springer: Berlin, 1974; Vol. 18

(4) Hobza, P.; Zahradník, R. Weak Intermolecular Interactions in Chemistry and Biology; Academia: Prague, 1980.

(5) Jeffrey, G. A.; Saenger, W. Hydrogen Bonding in Biological Structures; Springer: Berlin, 1991.

(6) Scheiner, S. Molecular Interactions. From van der Waals to Strongly Bound Complexes; Wiley: Chichester, 1997.

(7) Desiraju, G. R.; Steiner, T. The Weak Hydrogen Bond in Structural Chemistry and Biology; Oxford University Press: Oxford, 1999.

(8) Grabowski, S. J. Hydrogen Bonding - New Insights. Challenges and Advances in Computational Chemistry and Physics; Springer: Dordrecht, 2006.

(9) Maréchal, Y. The Hydrogen Bond and the Water Molecule; Elsevier: Amsterdam, 2007.

(10) Pauling, L. The Nature of the Chemical Bond; Cornell University Press, Ithaca, NY, 1960.

(11) Stone, A. J. Distributed multipole analysis, or how to describe a molecular charge distribution. Chem. Phys. Lett. 1981, 83, 233-239.

(12) Buckingham, D. A.; Fowler, P. W. Do electrostatic interactions predict structures of van der Waals molecules? J. Chem. Phys. 1983, 79, 6426-6428.

(13) Spackman, M. A. A simple quantitative model of hydrogen bonding. J. Chem. Phys. 1986, 85, 6587-6601.

(14) Puranik, P. G.; Kumar, V. Charge transfer theory of the H bond. Proc. Indian Acad. Sci. 1963, A58, 29-37.

(15) Bratož, S. Electronic Theories of Hydrogen Bonding. Advan. Quantum Chem. 1967, 3, 209-237.

(16) Ratajczak, H. Charge-Transfer Properties of the Hydrogen Bond. I. Theory of the Enhancement of Dipole Moment of HydrogenBonded Systems. J. Phys. Chem. 1972, 76, 3000-3004.

(17) Poater, J.; Fradera, X.; Solà, M.; Duran, M.; Simon, S. On the electron-pair nature of the hydrogen bond in the framework of the atoms in molecules theory. Chem. Phys. Lett. 2003, 369, 248-255.

(18) Hugas, D.; Simon, S.; Duran, M.; Fonseca Guerra, C.; Bickelhaupt, F. M. Dihydrogen Bonding: Donor-Acceptor Bonding
(AH...HX) versus the $\mathrm{H}_{2}$ Molecule (A- $\left.\mathrm{H}_{2}-\mathrm{X}\right)$. Chem.-Eur. J. 2009, 15, 5814-5822.

(19) Isaacs, E.; Shukla, A.; Platzman, P. M.; Hamann, D. R.; Barbiellini, B.; Tulk, C. A. Covalency of the Hydrogen Bond in Ice: A Direct X-Ray Measurement. Phys. Rev. Lett. 1999, 82, 600-603.

(20) Arunan, E.; Desiraju, G. R.; Klein, R. A.; Sadlej, J.; Scheiner, S.; Alkorta, I.; Clary, D. C.; Crabtree, R. H.; Dannenberg, J. J.; Hobza, P.; Kjaergaard, H. G.; Legon, A. C.; Mennucci, B.; Nesbitt, D. J. Defining the hydrogen bond: An account (IUPAC Technical Report). Pure Appl. Chem. 2011, 83, 1619-1636.

(21) Arunan, E.; Desiraju, G. R.; Klein, R. A.; Sadlej, J.; Scheiner, S.; Alkorta, I.; Clary, D. C.; Crabtree, R. H.; Dannenberg, J. J.; Hobza, P.; Kjaergaard, H. G.; Legon, A. C.; Mennucci, B.; Nesbitt, D. J. Definition of the hydrogen bond (IUPAC Recommendations 2011). Pure Appl. Chem. 2011, 83, 1637-1641.

(22) Desiraju, G. R. A Bond by Any Other Name. Angew. Chem., Int. Ed. 2011, 50, 52-59.

(23) Pendás, A. M.; Blanco, M. A.; Francisco, E. The nature of the hydrogen bond: A synthesis from the interacting quantum atoms picture. J. Chem. Phys. 2006, 125, 184112-184132.

(24) Craw, J. S.; Bacskay, G. B. Quantum-chemical Studies of Hydrogen Bonding involving Thioxoketones, Thienols, Thioformaldehyde and Hydrogen Sulfide with Specific Reference to the Strength of Intramolecular Hydrogen Bonds. J. Chem. Soc. Faraday Trans. 1992, $88,2315-2321$.

(25) Buemi, G.; Zuccarello, F. Is the intramolecular hydrogen bond energy valuable from internal rotation barriers? J. Mol. Struct. (Theochem) 2002, 581, 71-85.

(26) Jabłoński, M.; Kaczmarek, A.; Sadlej, A. J. Estimates of the Energy of Intramolecular Hydrogen Bonds. J. Phys. Chem. A 2006, 110, 10890-10898.

(27) Jabłoński, M. Full vs. constrain geometry optimization in the open-closed method in estimating the energy of intramolecular chargeinverted hydrogen bonds. Chem. Phys. 2010, 376, 76-83.

(28) Jabłoński, M. Energetic and Geometrical Evidence of Nonbonding Character of Some Intramolecular Halogen $\cdots$ Oxygen and Other Y $\cdots$ Y Interactions. J. Phys. Chem. A 2012, 116, 3753-3764.

(29) Schuster, P. LCAO-MO-Beschreibung intramolekularer Wasserstoffbrücken. Mh. Chem. 1969, 100, 2084-2095.

(30) Schuster, P. The Hydrogen Bond, Vol. I; Schuster, P., Zundel, G., Sandorfy, C., Eds.; North-Holland: Amsterdam, The Netherlands, 1976.

(31) Murthy, A. S. N.; Rao, C. N. R. Recent theoretical studies of the hydrogen bond. J. Mol. Struct. 1970, 6, 253-282.

(32) Estácio, S. G.; do Couto, P. C.; Costa Cabral, B. J.; Minas da Piedade, M. E.; Martinho Simoes, J. A. Energetics of Intramolecular Hydrogen Bonding in Di-substituted Benzenes by the ortho-para Method. J. Phys. Chem. A 2004, 108, 10834-10843.

(33) Roy, D.; Sunoj, R. B. Quantification of Intramolecular Nonbonding Interactions in Organochalcogens. J. Phys. Chem. A 2006, 110, 5942-5947.

(34) Buemi, G.; Zuccarello, F.; Venuvanalingam, P.; Ramalingam, M.; Ammal, S. S. C. Ab initio study of formazan and 3-nitroformazan. J. Chem. Soc., Faraday Trans. 1998, 94, 3313-3319.

(35) Buemi, G.; Zuccarello, F.; Venuvanalingam, P.; Ramalingam, M. $\mathrm{Ab}$ initio study of tautomerism and hydrogen bonding of $\beta$ carbonylamine in the gas phase an in water solution. Theor. Chem. Acc. 2000, 104, 226-234.

(36) Hehre, W. J.; Ditchfield, R.; Radom, L.; Pople, J. A. Molecular Orbital Theory of the Electronic Structure of Organic Compounds. V. Molecular Theory of Bond Separation. J. Am. Chem. Soc. 1970, 92, 4796-4801.

(37) George, P.; Trachtman, M.; Bock, C. W.; Brett, A. M. An Alternative Approach to the Problem of Assessing Stabilization Energies in Cyclic Conjugated Hydrocarbons. Theor. Chim. Acta (Berl.) 1975, 38, 121-129.

(38) Hehre, W. J.; Radom, L.; von Schleyer, P.; Pople, J. A. Ab Initio Molecular Orbital Theory; Wiley: New York, 1986. 
(39) Jabłoński, M. Enaminoketony: teoretyczne badania dynamiki wewnatrzmolekularnej w uktadzie modelowym 3-aminoakroleiny. M. Sc. Thesis, Nicolaus Copernicus University, Torun, Poland, 2000.

(40) Nowroozi, A.; Raissi, H.; Farzad, F. The presentation of an approach for estimating the intramolecular hydrogen bond strength in conformational study of $\beta$-Aminoacrolein. J. Mol. Struct. (Theochem) 2005, 730, 161-169.

(41) Espinosa, E.; Molins, E.; Lecomte, C. Hydrogen bond strengths revealed by topological analyses of experimentally observed electron densities. Chem. Phys. Lett. 1998, 285, 170-173.

(42) Deshmukh, M. M.; Gadre, S. R.; Bartolotti, L. J. Estimation of Intramolecular Hydrogen Bond Energy via Molecular Tailoring Approach. J. Phys. Chem. A 2006, 110, 12519-12523.

(43) Deshmukh, M. M.; Suresh, C. H.; Gadre, S. R. Intramolecular Hydrogen Bond Energy in Polyhydroxy Systems: A Critical Comparison of Molecular Tailoring and Isodesmic Approaches. J. Phys. Chem. A 2007, 111, 6472-6480.

(44) Deshmukh, M. M.; Bartolotti, L. J.; Gadre, S. R. Intramolecular Hydrogen Bonding and Cooperative Interactions in Carbohydrates via the Molecular Tailoring Approach. J. Phys. Chem. A 2008, 112, 312321.

(45) Deshmukh, M. M.; Gadre, S. R. Estimation of $\mathrm{N}-\mathrm{H} \cdots \mathrm{O}=\mathrm{C}$ Intramolecular Hydrogen Bond Energy in Polypeptides. J. Phys. Chem. A 2009, 113, 7927-7932.

(46) Grabowski, S. J. An estimation of strength of intramolecular hydrogen bonds - ab initio and AIM studies. J. Mol. Struct. 2001, 562, 137-143.

(47) Nikolaienko, T. Y.; Bulavin, L. A.; Hovorun, D. M. Bridging QTAIM with vibrational spectroscopy: the energy of intramolecular hydrogen bonds in DNA-related biomolecules. Phys. Chem. Chem. Phys. 2012, 14, 7441-7447.

(48) Bader, R. F. W. Atoms in Molecules: A Quantum Theory; Oxford University Press: New York, 1990.

(49) Popelier, P. L. A. Atoms in Molecules. An Introduction; Longman: Singapore, 2000.

(50) Bader, R. F. W. A Bond Path: A Universal Indicator of Bonded Interactions. J. Phys. Chem. A 1998, 102, 7314-7323.

(51) Matta, C. F.; Castillo, N.; Boyd, R. J. Characterization of a Closed-Shell Fluorine-Fluorine Bonding Interaction in Aromatic Compounds on the Basis of the Electron Density. J. Phys. Chem. A 2005, 109, 3669-3681.

(52) Vila, A.; Mosquera, R. A. On the perfluorination of alkyl ethers. An electron density study under the AIM approach. J. Mol. Struct. (Theochem) 2001, 546, 63-72.

(53) Palusiak, M.; Grabowski, S. J. Do intramolecular halogen bonds exist? Ab initio calculations and crystal structures' evidences. Struct. Chem. 2007, 18, 859-865.

(54) Cioslowski, J.; Mixon, S. T.; Edwards, W. D. Weak Bonds in the Topological Theory of Atoms in Molecules. J. Am. Chem. Soc. 1991, 113, 1083-1085.

(55) Cioslowski, J.; Mixon, S. T. Topological Properties of Electron Density in Search in Steric Interactions in Molecules: Electronic Structure Calculations on Ortho-Substituted Biphenyls. J. Am. Chem. Soc. 1992, 114, 4382-4387.

(56) Cioslowski, J.; Mixon, S. T. Universality among topological properties of electron density associated with the hydrogen-hydrogen nonbonding interactions. Can. J. Chem. 1992, 70, 443-449.

(57) Cioslowski, J.; Edgington, L.; Stefanov, B. B. Steric Overcrowding in Perhalogenated Cyclohexanes, Dodecahedranes, and [60]Fulleranes. J. Am. Chem. Soc. 1995, 117, 10381-10384.

(58) Haaland, A.; Shorokhov, D. J.; Tverdova, N. V. Topological Analysis of Electron Densities: Is the Presence of an Atomic Interaction Line in an Equilibrium Geometry a Sufficient Condition for the Existence of a Chemical Bond? Chem.-Eur. J. 2004, 10, 44164421.

(59) Poater, J.; Solà, M.; Bickelhaupt, F. M. Hydrogen-Hydrogen Bonding in Planar Biphenyl, Predicted by Atoms-In-Molecules Theory, Does Not Exist. Chem.-Eur. J. 2006, 12, 2889-2895.
(60) Poater, J.; Solà, M.; Bickelhaupt, F. M. A Model of the Chemical Bond Must Be Rooted in Quantum Mechanics, Provide Insight, and Possess Predictive Power. Chem.-Eur. J. 2006, 12, 2902-2905.

(61) Strenalyuk, T.; Haaland, A. Chemical Bonding in the Inclusion Complex of $\mathrm{He}$ in Adamantane (He@adam): The Origin of the Barrier to Dissociation. Chem.-Eur. J. 2008, 14, 10223-10226.

(62) Cerpa, E.; Krapp, A.; Vela, A.; Merino, G. The Implications of Symmetry of the External Potential on Bond Paths. Chem.-Eur. J. 2008, 14, 10232-10234.

(63) Cerpa, E.; Krapp, A.; Flores-Moreno, R.; Donald, K. J.; Merino, G. Influence of Endohedral Confinement on the Electronic Interaction between He atoms: A He $\mathrm{HC}_{20} \mathrm{H}_{20}$ Case Study. Chem.-Eur. J. 2009, $15,1985-1990$.

(64) Grimme, S.; Mück-Lichtenfeld, C.; Erker, G.; Kehr, G.; Wang, H.; Beckers, H.; Willner, H. When Do Interacting Atoms Form a Chemical Bond? Spectroscopic Measurements and Theoretical Analyses of Dideuteriophenanthrene. Angew. Chem., Int. Ed. 2009, $48,2592-2595$.

(65) Dem'yanov, P.; Polestshuk, P. A Bond Path and an Attractive Ehrenfest Force Do Not Necessarily Indicate Bonding Interactions: Case Study on $\mathrm{M}_{2} \mathrm{X}_{2}(\mathrm{M}=\mathrm{Li}, \mathrm{Na}, \mathrm{K} ; \mathrm{X}=\mathrm{H}, \mathrm{OH}, \mathrm{F}, \mathrm{Cl})$. Chem.-Eur. J. 2012, 18, 4982-4993.

(66) Jabłoński, M.; Palusiak, M. The halogen ․oxygen interaction in 3-halogenopropenal revisited - The dimer model vs. QTAIM indications. Chem. Phys. 2013, 415, 207-213.

(67) Jabłoński, M.; Sadlej, A. J. Blue-Shifting Intramolecular C-H $\cdots \mathrm{O}$ Interactions. J. Phys. Chem. A 2007, 111, 3423-3431.

(68) Jabłoński, M. Blue-shifting intramolecular $\mathrm{C}-\mathrm{H} \cdots \mathrm{O}(\mathrm{S})$ contacts in sterically strained systems. J. Mol. Struct:: THEOCHEM 2007, 820, $118-127$.

(69) Blanco, M. A.; Pendás, A. M.; Francisco, E. Interacting Quantum Atoms: A Correlated Energy Decomposition Scheme Based on the Quantum Theor of Atoms in Molecules. J. Chem. Theory Comput. 2005, 1, 1096-1109.

(70) Pendás, A. M.; Francisco, E.; Blanco, M. A.; Gatti, C. Bond Paths as Privileged Exchange Channels. Chem.-Eur. J. 2007, 13, 9362-9371.

(71) Tognetti, V.; Joubert, L. On the physical role of exchange in the formation of an intramolecular bond path between two electronegative atoms. J. Chem. Phys. 2013, 138, 24102-24109.

(72) Koch, U.; Popelier, P. L. A. Characterization of C-H-O Hydrogen Bonds on the Basis of the Charge Density. J. Phys. Chem. 1995, 99, 9747-9754.

(73) Grabowski, S. J. Ab Initio Calculations on Conventional and Unconventional Hydrogen Bonds-Study of the Hydrogen Bond Strength. J. Phys. Chem. A 2001, 105, 10739-10746.

(74) Grabowski, S. J. Ab initio and AIM studies on measures of hydrogen bonding strength-R-C $\equiv \mathrm{N} \cdots \mathrm{HF}$ and $\mathrm{R}-\mathrm{C} \equiv \mathrm{N} \cdots \mathrm{HCl}$ complexes. J. Mol. Struct. 2002, 615, 239-245.

(75) Shi, F.-Q.; An, J.-Y.; Yu, J.-Y. Theoretical Study on Measure of Hydrogen Bonding Strength: R-C $\equiv \mathrm{N} \cdots$ pyrrole Complexes. Chin. J. Chem. 2005, 23, 400-403.

(76) Grabowski, S. J. High-Level Ab Initio Calculations of Dihydrogen-Bonded Complexes. J. Phys. Chem. A 2000, 104, 55515557.

(77) Lipkowski, P.; Grabowski, S. J.; Robinson, T. L.; Leszczynski, J. Properties of the $\mathrm{C}-\mathrm{H} \cdots \mathrm{H}$ Dihydrogen Bond: An ab Initio and Topological Analysis. J. Phys. Chem. A 2004, 108, 10865-10872.

(78) Jabłoński, M.; Palusiak, M. Basis Set and Method Dependence in Atoms in Molecules Calculations. J. Phys. Chem. A 2010, 114, 2240-2244.

(79) Jabłoński, M.; Solà, M. Influence of Confinement on Hydrogen

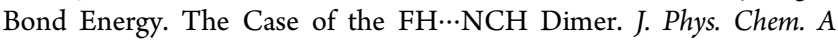
2010, 114, 10253-10260.

(80) McNaught, A. D.; Wilkinson, A. IUPAC. Compendium of Chemical Terminology, 2nd ed.; Blackwell Scientific Publications: Oxford, 1997. 
(81) Grabowski, S. J. Hydrogen bonding strength-measures based on geometric and topological parameters. J. Phys. Org. Chem. 2004, 17, $18-31$.

(82) Palusiak, M.; Simon, S.; Solà, M. Interplay between Intramolecular Resonance-Assisted Hydrogen Bonding and Aromaticity in $o$-Hydroxyaryl Aldehydes. J. Org. Chem. 2006, 71, 5241-5248.

(83) Rozas, I.; Alkorta, I.; Elguero, J. Intramolecular Hydrogen Bonds in ortho-Substituted Hydroxybenzenes and in 8-Susbtituted 1Hydroxynaphthalenes: Can a Methyl Group Be an Acceptor of Hydrogen Bonds? J. Phys. Chem. A 2001, 105, 10462-10467.

(84) Varnali, T.; Hargittai, I. Geometrical consequences of resonance-assisted hydrogen bonding in 2-nitrovinyl alcohol and indication of a slight attractive $\mathrm{O} \cdots \mathrm{H}$ interaction in 2-nitroethanol. An $\mathrm{ab}$ initio molecular orbital investigation. J. Mol. Struct. (Theochem) 1996, 388, 315-319.

(85) Wheeler, S. E.; Houk, K. N.; Schleyer, P. v. R.; Allen, W. D. A Hierarchy of Homodesmotic Reactions for Thermochemistry. J. Am. Chem. Soc. 2009, 131, 2547-2560.

(86) Frisch, M. J.; Trucks, G. W.; Schlegel, H. B.; Scuseria, G. E.; Robb, M. A.; Cheeseman, J. R.; Scalmani, G.; Barone, V.; Mennucci, B.; Petersson, G. A.; Nakatsuji, H.; Caricato, M.; Li, X.; Hratchian, H. P.; Izmaylov, A. F. et al. Gaussian 09, Revision B.01; Gaussian, Inc.: Wallingford CT, 2010.

(87) Møller, C.; Plesset, M. S. Note on an Approximation Treatment for Many-Electron Systems. Phys. Rev. 1934, 46, 618-622.

(88) Kendall, R. A.; Dunning, T. H., Jr.; Harrison, R. J. Electron affinities of the first-row atoms revisited. Systematic basis sets and wave functions. J. Chem. Phys. 1992, 96, 6796-6806.

(89) Davidson, E. R. Comment on "Comment on Dunning's correlation-consistent basis sets". Chem. Phys. Lett. 1996, 260, 514518.

(90) Ortiz, C. O.; Bo, C. Xaim. Universitat Rovira i Virgili: Tarragona. Spain,http://www.quimica.urv.es/XAIM/ (accessed November 2009).

(91) Kanji, G. K. 100 statistical tests.; Sage Publications Ltd: London, 1999.

(92) Gilli, G.; Bellucci, F.; Ferretti, F.; Bertolasi, V. Evidence for Resonance-Assisted Hydrogen Bonding from Crystal-Structure Correlations on the Enol Form of the $\beta$-Diketone Fragment. J. Am. Chem. Soc. 1989, 111, 1023-1028.

(93) Hobza, P.; Špirko, V.; Selze, H. L.; Schlag, E. W. Anti-Hydrogen Bond in the Benzene Dimer and Other Carbon Proton Donor Complexes. J. Phys. Chem. A 1998, 102, 2501-2504.

(94) Hobza, P.; Špirko, V.; Havlas, Z.; Buchhold, K.; Reimann, B.; Barth, H.-D.; Brutschy, B. Anti-hydrogen bond between chloroform and fluorobenzene. Chem. Phys. Lett. 1999, 299, 180-186.

(95) Hobza, P.; Havlas, Z. Blue-Shifting Hydrogen Bonds. Chem. Rev. 2000, 100, 4253-4264.

(96) Jabłoński, M.; Sadlej, A. J. Infrared and Raman Intensities in Proper and Improper Hydrogen-Bonded Systems. Pol. J. Chem. 2007, $81,767-782$.

(97) Li, X.; Liu, L.; Schlegel, H. B. On the Physical Origin of BlueShifted Hydrogen Bonds. J. Am. Chem. Soc. 2002, 124, 9639-9647.

(98) Joseph, J.; Jemmis, E. D. Red-, Blue-, or No-Shift in Hydrogen Bonds: A Unified Explanation. J. Am. Chem. Soc. 2007, 129, 46204632.

(99) Jabłoński, M.; Sadlej, A. J. Influence of the external pressure on improper character of intramolecular $\mathrm{C}-\mathrm{H} \cdots \mathrm{O}$ interactions. Chem. Phys. Lett. 2008, 463, 322-326.

(100) Parthasarathi, R.; V. Subramanian, V.; Sathyamurthy, N. Hydrogen Bonding without Borders: An Atoms-in-Molecules Perspective. J. Phys. Chem. A 2006, 110, 3349-3351.

(101) Dominiak, P. M.; Makal, A.; Mallinson, P. R.; Trzcinska, K.; Eilmes, J.; Grech, E.; Chruszcz, M.; Minor, W.; Woźniak, K. Continua of Interactions between Pairs of Atoms in Molecular Crystals. Chem.Eur. J. 2006, 12, 1941-1949.

(102) Boys, S. F.; Bernardi, F. The calculation of small molecular interactions by the differences of separate total energies. Some procedures with reduced errors. Mol. Phys. 1970, 19, 553-566.
(103) Berlin, T. Binding Regions in Diatomic Molecules. J. Chem. Phys. 1951, 19, 208-213. 